This item was submitted to Loughborough's Institutional Repository (https://dspace.lboro.ac.uk/) by the author and is made available under the following Creative Commons Licence conditions.

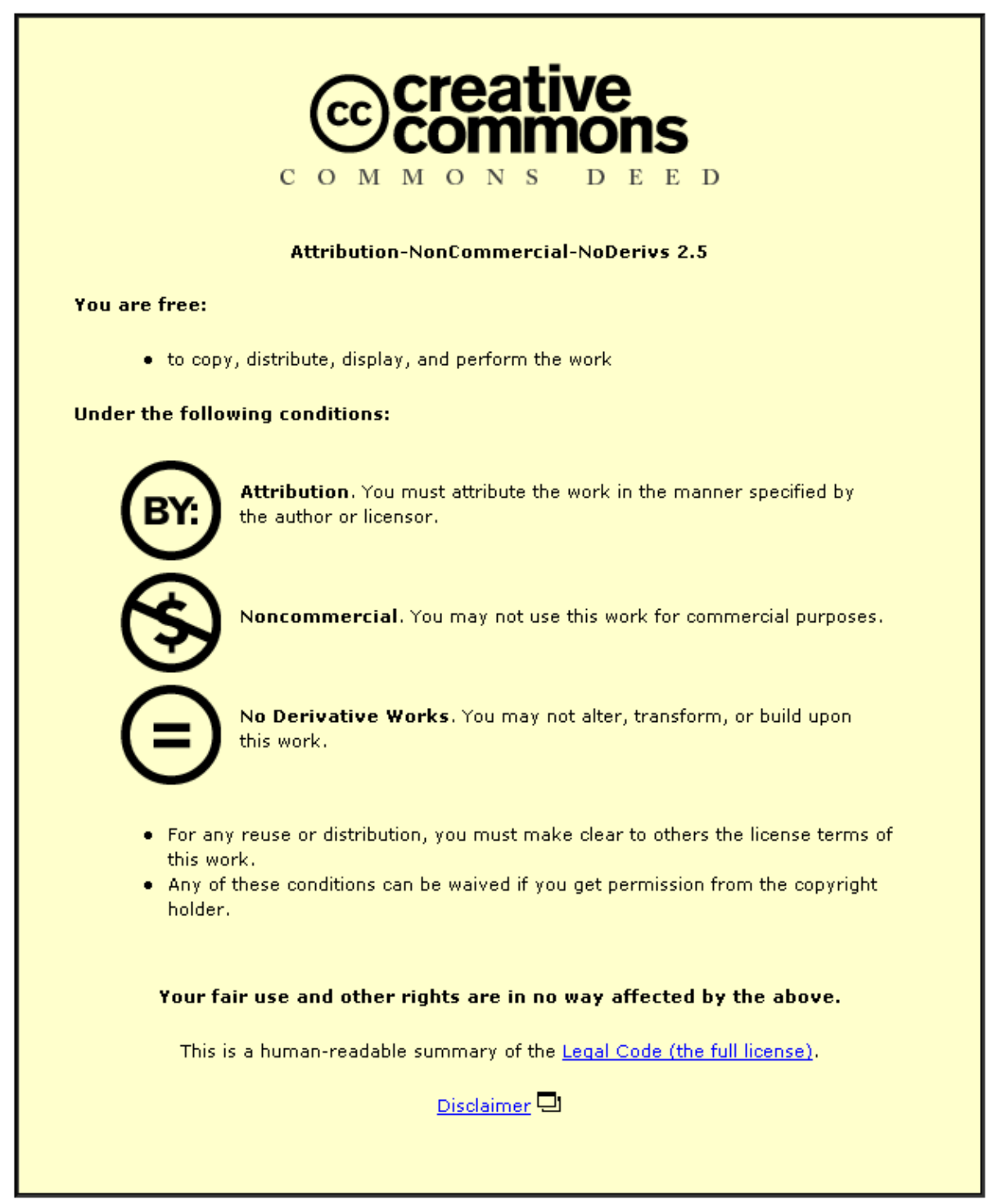

For the full text of this licence, please go to: http://creativecommons.org/licenses/by-nc-nd/2.5/ 


\title{
Mechanical Behaviour of Advanced Composite Laminates Embedded with Carbon Nanotubes - Review
}

\author{
Guanyan Xie ${ }^{\mathrm{a}}$, Gang Zhou ${ }^{\mathrm{b}}$ and Xujin Bao ${ }^{\mathrm{c}}$ \\ ${ }^{\text {a, c }}$ Department of Materials, Loughborough University, Loughborough LE11 3TU, UK \\ ${ }^{b}$ Department of Aeronautical and Automotive Engineering, Loughborough University, \\ Loughborough LE11 3TU, UK
}

\begin{abstract}
Embedding carbon nanotubes (CNTs) in load-bearing composite laminate hosts and thereby turning them into nanolaminates is a rapidly emerging field and has tremendous potential in enhancing mechanical performance of host laminates. This state-of-the-art review intends to provide physical insight into the understanding of enhancing mechanisms of processed and controlled CNTs in nano-laminates. It focuses on four aspects: (1) physical characteristics of CNTs including CNT length, diameter and weight percentage; (2) processing and control techniques of CNTs in fabrication of nano-laminates including distribution, dispersion and orientation controls of CNTs; (3) mechanical properties along with their testing methods including tension, in-plane compression, interlaminar shear (ILS), flexure, mode I and mode II fracture toughness as well as compression-after-impact (CAI); and (4) post-mortem microscopic corroborative evidence after mechanical testing.

As this review indicates, selective and uniform production of CNTs with specific dimensions and physical properties has yet to be achieved on a consistent basis. There is little control over CNT orientations in most fabrication processes of nano-laminates except for some cases associated with chemical vapour deposition (CVD). There are only two reports on the in-plane compression and there is none on in-plane shear. For reinforcement-dominated mechanical properties such as tension and flexure, there is little enhancement as reported. However, substantial enhancement in in-plane compression strength was reported. For matrix-dominated mechanical properties such as ILS strength and mode-I and mode-II fracture toughness, significant enhancement, albeit with substantially varying degrees, has been reported. In the meanwhile, the lack of consistent characterisation in those properties was also noticeable. Post-mortem microscopic corroborative evidence was very limited.
\end{abstract}

\section{Keywords: carbon nanotubes (CNTs), nano-laminates, mechanical properties}

\section{INTRODUCTION}

Fibre-reinforced composite laminates have been extensively used in various sectors of industry, including aerospace, land transport and marine, to name just a few. The majority of those composite laminates in use lack reinforcement in the through-the-thickness direction. As a result, a damage mechanism such as delamination could occur at the relatively early stage of loading when induced local ILS stress within the laminate reaches a critical level, thereby affecting their structural performance. Delamination is thus one of most detrimental damage mechanisms and causes considerable problems to structure designer, stress and maintenance engineers. At present, load-bearing composite laminates are designed such that the occurrence of delamination is minimised. This practice often leads to that composite laminates are over-weight, less cost-effective and less efficient in terms of performance. Over the years, various solutions such as resin-toughening, stitching, interleaving and z-pinning have been experimented but with limited success. Some of these techniques could improve the delamination resistance of the composite laminates to some extent but at the expense of substantial reduction of their basic mechanical properties. The recent advent of CNTs provides many exciting possibilities to engineering exploitations. One particular area of innovation is to introduce CNTs into composite laminates to enhance their resin-dominated mechanical properties so that their delamination resistance can be substantially improved.

${ }^{\mathrm{b}}$ Author to whom the correspondence should be addressed. G.Zhou@Lboro.ac.uk 
CNTs can be both single-walled (SWNTs) and multi-walled CNTs (MWNTs). They have a nominal diameter between 2 and 100 nano-meter (nm) and a length between tens and hundreds of a micron, depending on their manufacturing techniques and their surface functional coatings. These dimensions typically result in aspect ratio of at least two orders of magnitude. They have a Young's modulus of around one TPa (or five times that of steel) and a strength of around twenty GPa (or one hundred times that of steel). Their elastic and failure strains are greater than $5 \%$ and $12 \%$, respectively. These physical features along with their mechanical properties make CNTs easily embeddable in a laminate host without imposing any substantial intrusion and ideal for enhancing the mechanical properties of resins. They are capable of playing a vital role in creating new-generation nano-laminates with enhanced mechanical performance. Because this field is very much emerging, there is little information in public domain on a link between enhancing mechanisms and associated processing details of CNTs. In particular, those research works as reviewed here reflect on many occasions results of their preliminary trials. Therefore, it is essential to have an in-depth and comprehensive overview of this field in this embryonic state such that the key and critical issues in the CNTs processing and control, nano-laminate manufacturing and enhancing mechanisms in the mechanical performance are highlighted. As a result, research efforts worldwide, especially from newcomers of entering this emerging field could be more focused on those issues and thereby chanelled into making greater progress rather than reinventing the wheel.

This paper intends to provide a state-of-the-art review of the published literature in this field [1-17] with exclusive attention being paid to experimental work. It aims ultimately at the establishment of a understanding of how and via what deformation mechanisms purposely processed and controlled CNTs influence the mechanical performance of the laminate host. It has four specific focuses. The first one is to identify manufacturing methods of nano-laminates along with introduction techniques of CNTs. The second one is to ascertain processing and control techniques with which CNTs are subjected to before/during the manufacturing of nano-laminates. At this stage, attention will be exclusively paid to dispersion and orientation controls of CNTs, the in-plane and through-the-thickness locations of CNTs in the nano-laminates and the role played by the length of and volume fraction of CNTs. The third one examines types of mechanical properties and testing methods used. For the former, mechanical properties reviewed include tension, in-plane compression, in-plane shear and ILS, flexure, mode I and mode II fracture toughness as well as compression-after-impact (CAI) strength property. For the latter, critical discussion will be carried out as for whether or not used testing methods are suited and/or adequate to the evaluation of the mechanical performance of nano-laminates. It is conceivable that testing methods which have already been established for conventional composite laminates are not necessarily automatically adequate to evaluate the mechanical performance of nanolaminates. The final one includes an investigation into post-mortem microscopic corroborative evidence after mechanical testing. This is crucial for providing physical insight into enhancing mechanisms of CNTs in the mechanical performance of nano-laminates.

To this end, it is essential to clearly define a scope of involvement of nanomaterials with conventional host materials in this review as numerous definitions or phrases have already appeared in open literatures. A definition of nanomaterials generally includes CNTs and nanoparticles, each of which can be used as filler, reinforcement, or functional material in a host material. Typical host materials are usually either polymers or fibre-reinforced composite laminates, though metals are also used on some occasions. A broad definition of nano-composites has been used extensively as one of three combinations, namely, (a) nanoparticles with conventional polymers, (b) nanoparticles with fibre-reinforced composite laminates and (c) CNTs with conventional polymers. The reason that the mixture of nanoparticles with conventional fibre-reinforced composite laminates is also included under nanocomposites is because nanoparticles with small aspect ratio are unable to provide any substantial improvement of mechanical properties. In particular, nano-composites except for this case are generally considered being homogeneous and isotropic even on a microscopic scale so that their mechanical testing standards follow those of metals and plastics. Here, nano-laminates are defined as a mixture of conventional fibre-reinforced composite laminates as host and CNTs as nanomaterial. Since in a nano-laminate, continuous reinforcement, say carbon or Eglass fibres, is already present, short CNTs are no longer called reinforcement. Thus, mechanical testing standards of nano-laminates tend to adopt those which have already been developed for conventional composite laminates. The present review covers only the mechanical behaviour of nano-laminates while the mechanical behaviour of nanocomposites has been comprehensively reviewed in [18-21] so that it will not be repeated here. It is the first time that 
the mechanical behaviour of nano-laminates has been reviewed. In addition, the terms of fibres, reinforcement and matrix thereafter refer repectively to those conventionally used in host composite laminates.

\section{MANUFACTURING METHODS OF NANO-LAMINATES}

Manufacture of nano-laminates is a very complex process due primarily to the fact that it is generally difficult to disperse CNTs and control their orientations and is even more difficult to introduce so processed CNTs into a conventional laminate host and keep them in such state successfully during cure. As a result, in addition to different manufacturing methods, there are a significant number of material and processing parameters, as indicated in Table 1 , which could influence a quality and thus mechanical performance of nano-laminates.

\subsection{Material characteristics of laminate hosts and CNTs}

Laminate hosts that have been used in nano-laminates so far are usually composed of either carbon or E-glass fibres and polymeric matrix such as epoxy, polyester, or vinyl ester. While epoxy is the most dominant matrix material, both carbon and E-glass fibres are equally popular. Their weave patterns in a host laminate seem to be influenced by a manufacturing method of the nano-laminates with unidirectional (UD) being used with autoclave and fabric preforms used with VARTM (vacuum assisted resin transfer moulding), see Table 1.

The physical characteristics of used CNTs as shown in Table 1 vary significantly, dependent on their production method and on whether they are SWNTs or MWNTs. SWNTs are usually smaller in diameter and shorter in length than MWNTs with better mechanical properties. Three major production methods for CNTs are electric arch discharge [6], laser ablation of metal-doped carbon rods and CVD [1-3,5,8,10,12,15]. While the first two methods produce high quality CNTs in general, they are neither able to produce only SWNTs nor able to control their lengths. In addition, they have low yield. CVD and its variants seem most popular because of their ability of overcoming those limitations. Firstly, CVD is capable of synthesising only SWNTs via HiPco (variant of CVD with high temperature and high pressure) [9]. Secondly, it is capable of controlling CNT length and growth direction. For instance, vertically aligned CNTs, called CNT forest, could be grown. Finally, CNTs can be grown in-situ directly from the surface of fabric preforms. The other additional useful features include its relatively low cost and versatility, say, growing CNTs as stacked truncated cups (CSCNTs) [10,11,15]. It is not surprising that CVDproduced CNTs dominated applications in nano-laminates. However, there are published reports [22] which suggest that the quality of CNTs produced by CVD were not as good as those produced by the other two methods. Nevertheless, it still seems challenging to produce a particular type of CNTs, say SWCNTs, with uniform dimensions and physical properties. In addition, as the natural surface of CNTs is smooth, they often do not bond well with a resin of the laminate host. Thus it is desirable to attach various functional groups to CNTs so that a good interfacial bonding with the matrix of the host laminate could be obtained.

\subsection{Manufacturing methods for laminate hosts}

Typical manufacturing methods that have been used to fabricate flat laminate hosts are VARTM, autoclave moulding, compression moulding (including hot pressing) and hand lay-up. Autoclave moulding as a well established predominant method in the aerospace industry usually uses prepregs as starting materials in a doublesided mould. With a precise control over time, temperature and pressure, laminates of high quality are produced routinely. Naturally, it has been used to fabricate nano-laminates as in [1,10-12,15]. VARTM has been equally popular due to its possibility of using dry fabrics and liquid resins as starting materials, low tooling requirement and low cost $[3,4,6,8,9,13,16,17]$. As a single-sided mould is usually used under atmospheric pressure in VARTM, it has the limited ability to consolidate laminates and thereby control the thickness of laminates. Thus an uniform infiltration of the resin doped with CNTs could be difficult, especially when the amount of CNTs is significant, due to a relatively high viscosity of the resin at room temperature and relatively high surface area of CNTs. This could be compounded by relatively long CNTs, if used, as they could reduce resin flow rate and increase resin viscosity and thereby processing difficulty. However, this process was further improved by using double vacuums and was renamed as IDVARTM [3]. As a result, up to $2 \mathrm{wt} \%$ concentration of CNTs was successfully introduced into the laminate host. 
Compression moulding is another low cost method for fabricating host laminates [2,14]. It usually has a pair of heated pressing platens for applying pressure but with no vacuum environment. Starting materials can be either dry fabrics with liquid resin or prepregs. Pressure is applied to a laminate either directly or via an additional moulding tool. Hand lay-up is the simplest method of all, using usually dry fabrics and liquid resin as starting materials along with a single-sided mould [5,7]. As resin is brushed or sprayed onto the fabrics layer after layer, there is little control over the quality of laminates without consolidation pressure.

\subsection{Processing techniques for introduction of CNTs into laminate hosts}

While autoclave moulding is still the most predominant method for fabricating high quality laminates, VARTM has become the most effective non-autoclave low-cost method. Nevertheless, the merits of the methods as techniques for fabricating nano-laminates ultimately rest on their effectiveness in controlling or maintaining an uniform distribution and especially orientation of CNTs within the host. Three techniques that have been used to introduce CNTs into a host laminate are based on doping, growth and transplanting or insertion, respectively.

Doping technique so far seems the most straightforward and popular technique of introducing CNTs into a host laminate as it could be used along with any one of the aforementioned laminate assembly and curing methods such as VARTM, autoclave and compression moulding. CNTs were first dispersed in a liquid resin via a simple mixing or 3-roll milling. Then doped resin was drawn through fabric preforms stacked in a mould to allow its infiltration just as a usual operation of VARTM $[3,4,6,13,16,17]$. As a result, during infiltration there was little control over a uniformity of dispersed CNTs, let alone control of their orientations. The other way of making use of VARTM was to either soak fabric preforms in a solution dispersed with CNTs [8] or spray CNTs dispersed liquid onto fabric preforms [9]. The fabric preforms then had CNTs stuck on their surfaces once suspension liquid dried up. A final usual operation of resin infiltration was carried out to produce a nano-laminate. An advantage of the fabric doping techniques is that not all fabric layers need to be doped so that they could be used cost-effectively for wherever enhancement of mechanical performance is desired. Alternatively, doped resin could be poured onto dry fabric layers individually and then all individual layers were stacked up to be cured using an autoclave [10-12,15]. The advantage of this process was that it also allowed additional CNTs to be either sprinkled or inserted in the form of film at selected through-the-thickness location. Another alternative to an autoclave was to cure nan-laminates via compression moulding [14].

Growth technique started with either soaking individual fabric preforms in a solution [5] or spraying liquid catalyst onto two surfaces of individual fabric preforms [7]. Under high temperature, CNTs then grew from catalyst precursor deposited on the fabric surface of preforms with the aid of blended gases within a furnace as part of a CVD process. The direction of the growth was controlled by application of strong electron field. Fabric preforms with grown CNTs on their surface were soaked in resin. These individual layers were stacked up and finally cured either with a vacuum bag [5] or at room temperature [7].

Transplanting or insertion technique started with either planting/growing CNTs on a silicon wafer via a CVD process $[1,2]$ or fabrication of nano-composite films [11,14]. For the former, CNTs arrays or forest were then mechanically transplanted onto individual conventional host prepreg surface [1,2]. Finally, those individual prepregs were stacked up and were cured either using an autoclave [1] or with compression moulding [2]. Since grown CNT arrays were parallel to one another, transplanted CNTs were supposed to be in theory perpendicular to the prepreg surface. If so oriented CNTs survive the lamination process and pressure during cure, they could be effective barriers to the occurrrence of delaminations. For the latter, nano-composite films were prepared with semi-cured resins. These films were then inserted at selected through-the-thickness locations during conventional lay-up. Finally, naolaminate stacks were cured either using an autoclave [11] or with compression moulding [14]. It was unclear whether CNTs in the film were random or orientation-controlled. The advantage of this transplanting/insertion technique was that it allowed CNTs to be inserted at selected through-the-thickness locations.

Throughout all three techniques, weight percentage (indicated by wt $\%$ ) of, length, uniformity of dispersion and orientation of CNTs will all affect the mechanical behaviour of nano-laminates. Being too long is not necessarily helpful. Detailed microscopic physical characterisation for the uniformity of dispersion and orientation of CNTs at specific locations is often not available. 


\section{TYPES OF FUNDAMENTAL MECHANICAL PROPERTIES OF NANO-LAMINATES}

The mechanical behaviour of nano-laminates was characterised by both modulus and strength properties in tension, in-plane compression, flexure, in-plane shear and ILS, mode I and mode II fracture toughness. All mechanical property results of reviewed publications in terms of average values plus standard deviations are summarised in Tables 2 and 3, including the baseline values of host laminates for specific properties. The corresponding details for physical characteristics of both CNTs and host laminates in addition to manufacturing methods can be looked up in Table 1 for the same reference numbers. Respective mechanical testing standards, which were indicated in Tables and 2 and 3, largely followed ASTM standards. Table 2 includes mechanical property results for tension, in-plane compression and flexure, which are generally considered to be dominated by the reinforcement of host laminates. The transverse tensile properties of UD laminates were also included in Table 2 together with the longitudinal properties for the sake of completeness, though their performance was deemed to be dominated by matrix. Table 3 includes mechanical property results for ILS, mode I and mode II fracture toughness, which are generally considered to be dominated by the matrix of host laminates. For clarity and ease of comparison, all original numerical results are also presented with bar charts in Figs 1-21, in which average baseline values were plotted against average values of nano-laminates with major contributing factors such as CNT weight percentage, a length and diameter of CNTs, CNT functionalisation and presence of dispersants being identified.

\subsection{Tension}

Table 2 summarises the tension results of both baseline laminates and nano-laminates with some of the comparable results being presented graphically in Figs $1-5$. All host laminates $[8,10,15,17]$ but one [16] used carbon/epoxy. Moreover, all laminates $[8,10,16,17]$ but one [15] were constructed with no more than eight plies in a lay-up of UD [15], cross ply (CP) $[8,10,17]$ and quasi-isotropic (QI) $[15,16]$. The majority $[8,10,15,17]$ followed ASTM D3039 standard [23] whereas one [16] used DIN EN 527.1/2 standard in their specimen preparation and test set-up. The results as shown in Table 2 and Figs 1-5 show that neither tensile modulus nor tensile strength was substantially enhanced even when the amount of CNTs was increased up to $10 \mathrm{wt} \%$ [15] or $12 \mathrm{wt} \%$ [10]. The amounts of increase and decrease in both modulus and strength are within or similar to the respective ranges of data scatters, when compared with those of baseline values. This is expected of the nano-laminates with a lay-up other than UD as some reinforcement of the nano-laminates was in the loading direction. However, it is interesting to note in Fig. 4 [15] that the transverse tensile strength of UD nano-laminates with $5 \mathrm{wt} \%$ CNTs was increased by $13 \%$ though the transverse tensile modulus was increased only by $6 \%$. As the transverse properties of UD nano-laminates are supposed to be matrix-dominated, an 13\% increase caused by an inclusion of $5 \mathrm{wt} \%$ CNTs could be viewed as modest. Nevertheless, no microscopic corroborative evidence was provided for fractured sections in [15]. In addition, these results also confirm that embedding CNTs in composite laminates does not affect adversely tensile properties.

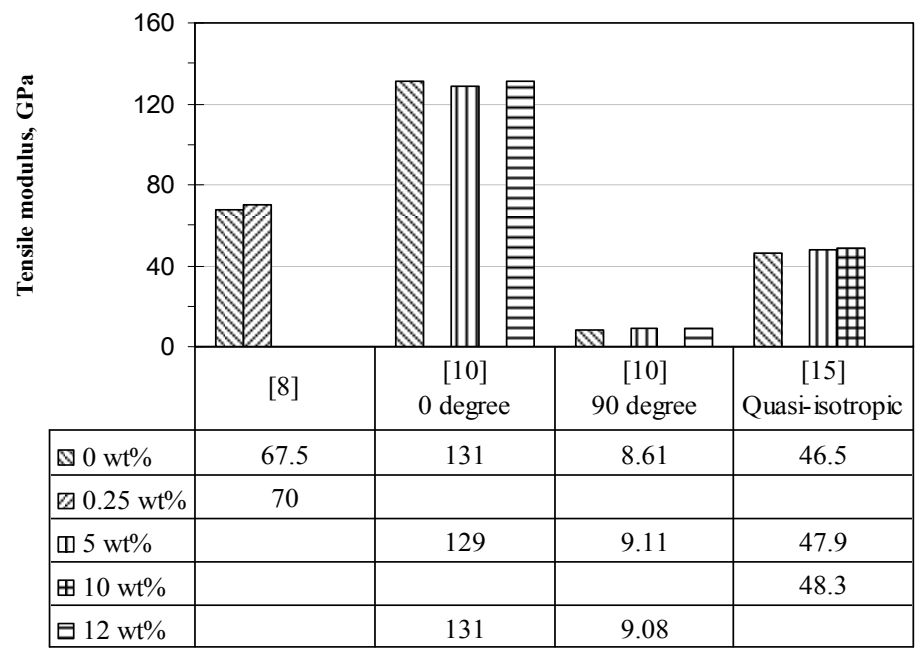

Fig. 1 Tensile moduli of nano-laminates with carbon/epoxy laminate hosts with various lay-ups from references [8,10,15] 


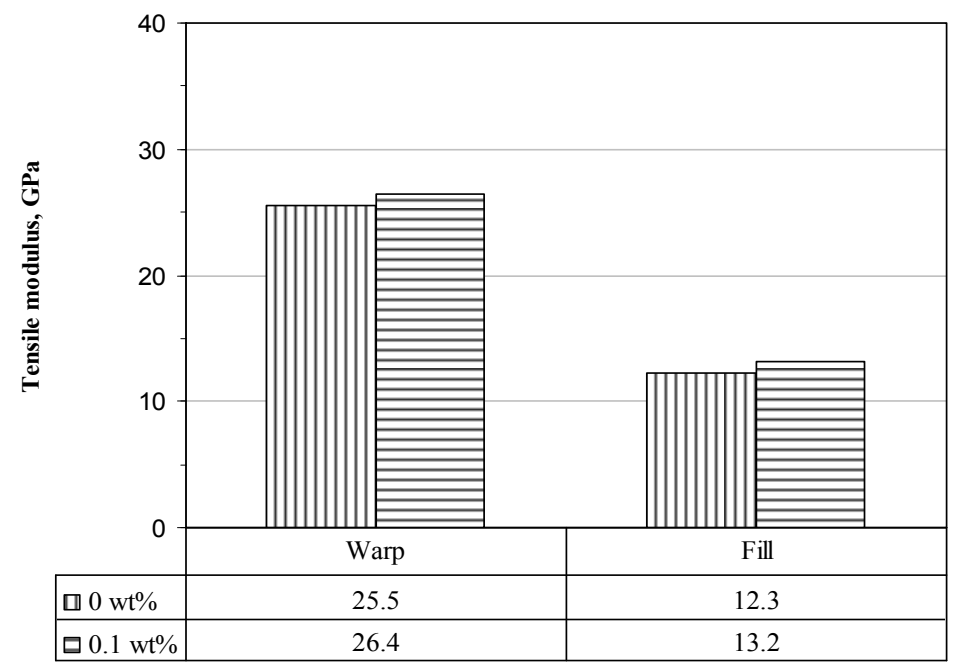

Fig. 2 Tensile moduli of nano-laminates with E-glass/epoxy fabric laminate hosts from reference [16]

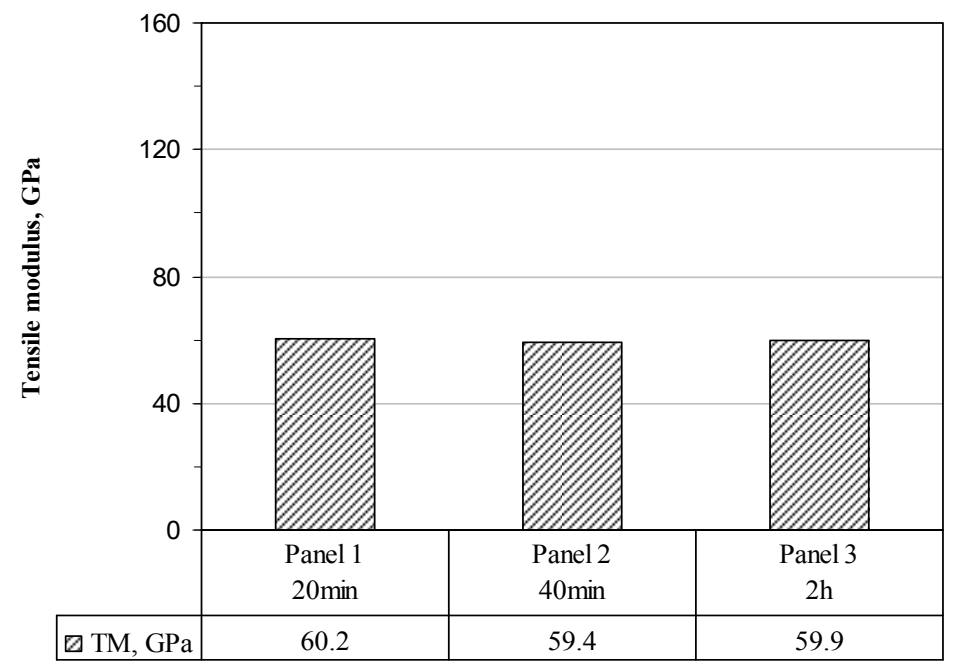

Fig. 3 Tensile moduli of nano-laminates with carbon/epoxy host with various infusion times in VARTM from reference [17]

\subsection{In-plane compression}

There is a dearth of information on in-plane compression results of nano-laminates [12,15] due probably to the wellknown complexity involved in jig requirement and assembly, if using ASTM D3410 standard [24], as well as test execution. Both groups of the authors $[12,15]$ used their own testing methods and neither provided details of compression load introduction techniques. The only investigation on compressive modulus from the latter investigators [15] shows in Fig. 6 that the compressive modulus of carbon/epoxy host with a QI lay-up was not affected by an inclusion of $10 \mathrm{wt} \%$ CNTs. However, the findings for compressive strength are slightly inconsistent from the two investigations. In [12], the authors examined the respective effects of dispersant and CNT length on compressive strength of carbon/epoxy hosts. Both nano-laminates were relatively thick with 48 plies in a CP lay-up [12] and 24 plies in a QI lay-up [15]. As shown in Fig. 7 and in Table 2, they found that for the short CNT length of $1 \mu \mathrm{m}$ the presence of CNTs with $1 \mathrm{wt} \%$ increased compressive strength by about $13 \%$ and the inclusion of dispersants doubled the strength increase. For the long CNT length of $10 \mu \mathrm{m}$, the presence of CNTs with $1 \mathrm{wt} \%$ increased compressive strength by about $23 \%$ and the inclusion of dispersants somewhat had little effect on compressive strength. Although the aspect ratio of 0.67 for gauge section of specimens [15] was deemed to be problematic to nano-laminates in a QI lay-up, their compressive strength results as shown in Fig. 8 and in Table 2 
show little effect of CNT inclusion, with $10 \%$ increase for $10 \mathrm{wt} \%$ CNTs. No microscopic corroborative evidence was given.

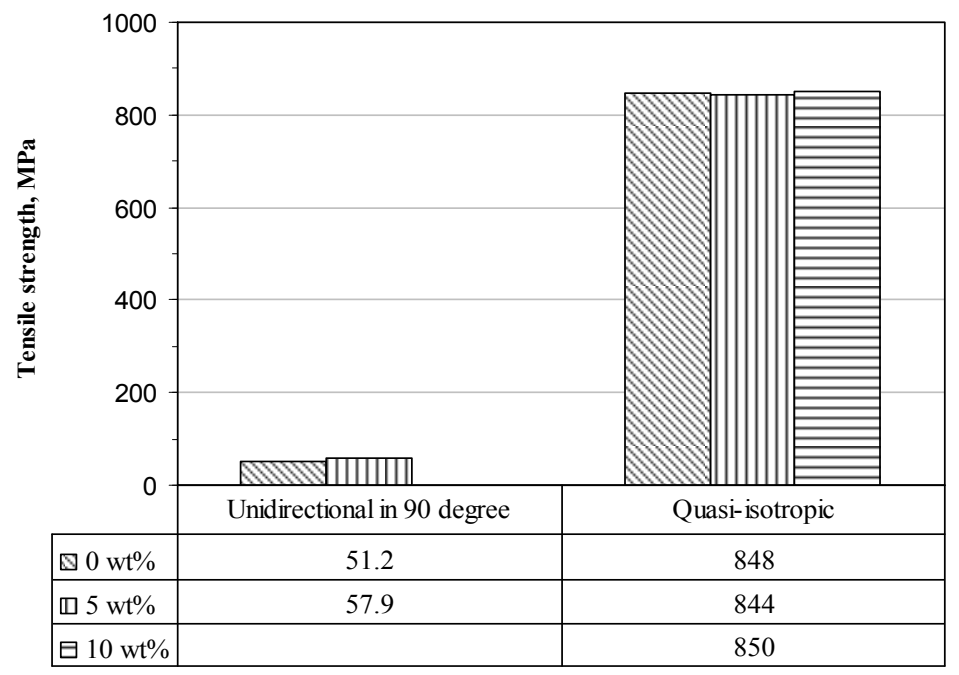

Fig. 4 Tensile strengths of nano-laminates with carbon/epoxy laminate host with two different lay-ups from reference [15]

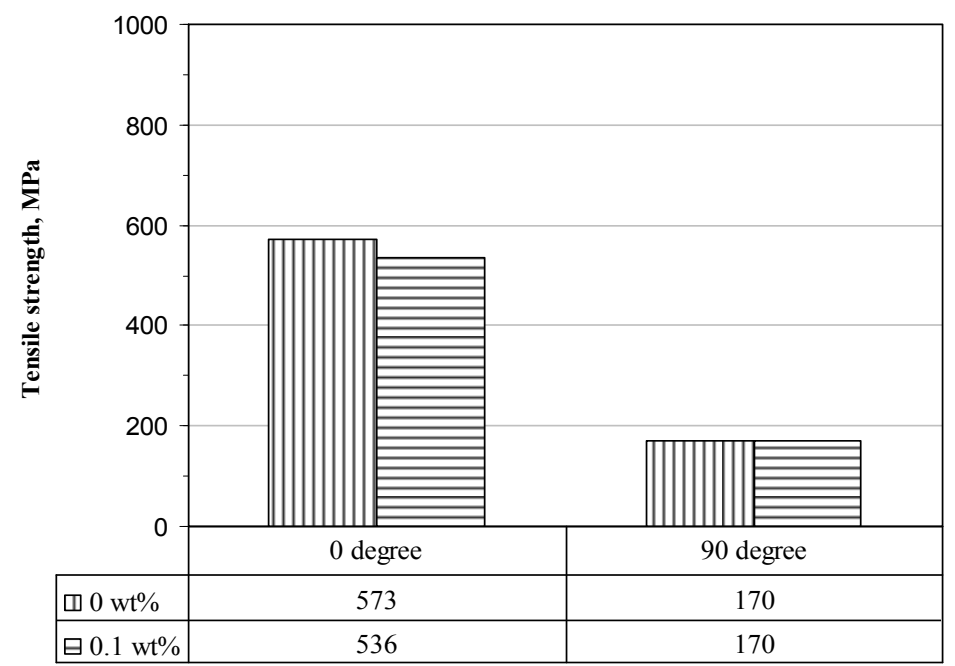

Fig. 5 Tensile strengths of nano-laminates with quasi-isotropic E-glass/epoxy laminate host from reference [16]

\subsection{Flexure}

There is not much information on flexure results of nano-laminates either $[4,6,15]$. All host laminates $[4,6,15]$ used carbon/epoxy composite systems in a lay-up of CP [4], UD [6] and QI [15], respectively. Nano-laminates were tested with a length-to-depth ratio of 16 [4], 32 [6] and 27 [15], following broadly 3-point bending method from ASTM D790 standard [25]. Their results in Table 2 show that neither flexural modulus, also in Fig. 9, nor flexural strength, also in Fig. 10, was increased beyond their respective ranges of scatter. Although the amount of CNTs used in $[4,6]$ was very small, this was still the case with the amount of CNTs used being increased up to $10 \mathrm{wt} \%$ [15]. Although these findings are in accordance with those of the earlier tensile tests, they are interesting as the nano-laminates in bending would normally fail on the compressive side of the beam surfaces. As a result, some degree of enhancement should have been exhibited, providing that the limited findings from in-plane compression were reliable. Clearly, further investigation of this aspect will be necessary in future in order to clear up this significant discrepancy. 


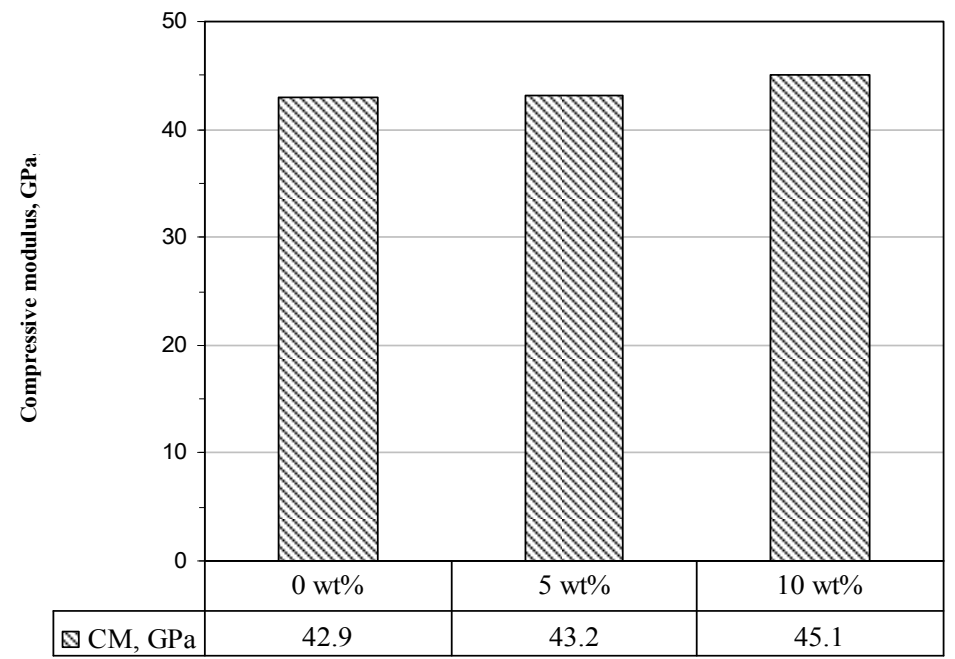

Fig. 6 In-plane compression moduli of nano-laminates with quasi-isotropic carbon/epoxy laminate host from reference [15]

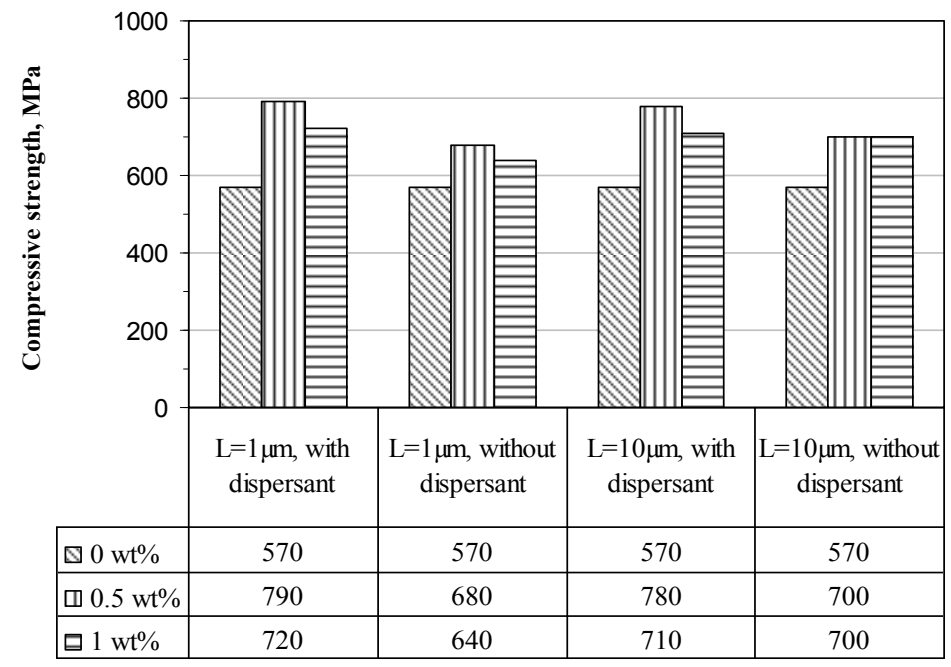

Fig. 7 In-plane compression strengths of nano-laminates with carbon/epoxy laminate host with various CNT and processing conditions from reference [12]

\subsection{In-plane shear}

Although in-plane shear is part of matrix-dominated mechanical behaviour, amazingly, it seems that so far no one has carried out any investigation on in-plane shear properties of nano-laminates, using either ASTM D3518 standard via $\pm 45^{\circ}$ tension [26] or ASTM D5379 standard via Iosipescu shear [27]. This can be interpreted as another evidence for the fact that this emerging field is indeed in an embryonic state.

\subsection{Interlaminar shear}

An investigation of ILS behaviour has so far attracted the greatest attention with a total of ten publications $[2,3,5,6,8,9,12-14,16]$. This is not surprising as the biggest impact of including CNTs in conventional composite laminates is expected to be in the area of ILS, as the latter is matrix-dominated due to the lack of the reinforcement in the laminate thickness direction. In particular, all investigations [2,3,5,6,8,9,12-14,16] but one [2] focused on ILS strength. While the majority of the investigations $[3,5,8,9,12,13,14,16]$ followed Short Beam Shear (SBS) ASTM D2344 standard [28], three other test methods were also used, namely, Iosipescu shear ASTM D5379 standard [27] 
in [2], Compression Shear Test (CST) [29] in [3] and unsymmetrical double-notch compression (DNC) ASTM D3846 standard [30] in [6]. Moreover, while carbon/epoxy host laminates used a length-to-depth ratio of 4 as recommended by SBS, E-glass fibre reinforced plastics (GFRP) (including matrix materials of epoxy, polyester and vinyl ester) adopted a length-to-depth ratio of 5, again as recommended. A lay-up of host laminates was dominated by CP $[2,3,8,9,12,14,16]$, followed by QI [13,16] with the remaining two being UD [6] and angle-ply (AP) [5], respectively. In addition, the majority $[2,5,6,8,13,14,16]$ of host laminates tested were only around $1 \mathrm{~mm}$ in thickness, except for those in [3,9,12]. All numerical results are given in Table 3 and some of ILS strength results are also presented graphically in Figs 11-16.

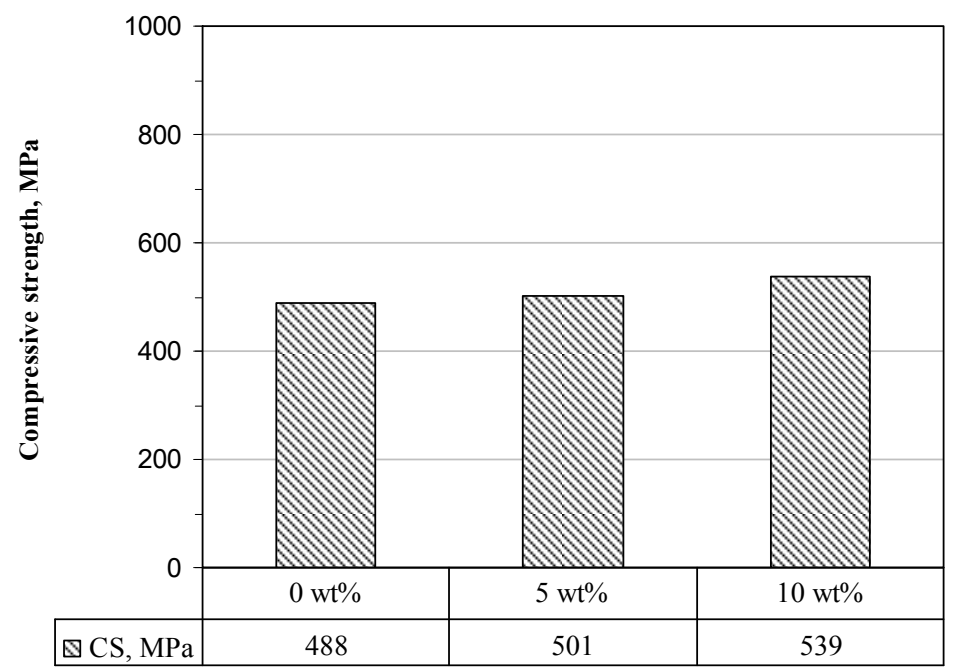

Fig. 8 In-plane compression strengths of nano-laminates with quasi-isotropic carbon/epoxy laminate host from reference [15]

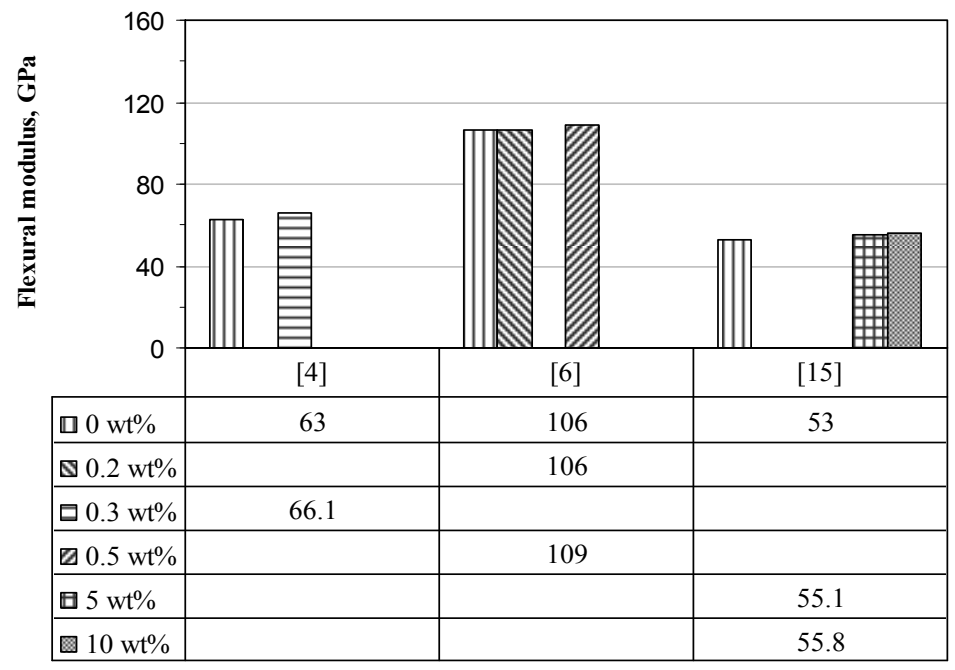

Fig. 9 Flexural moduli of nano-laminates with various carbon/epoxy laminate hosts from references $[4,6,15]$

For carbon/epoxy host laminates [2,6,8,12], all three testing standards, Iosipescu shear, DNC and SBS were used for their nano-laminates. The ILS strength results of nano-laminates (around $3.5 \mathrm{~mm}$ thick) associated with Iosipescu shear method [2] do not exhibit any enhancement as shown in Fig. 11, as might be expected, because the amount of CNTs included $(0.2 \mathrm{wt} \%)$ is very low. However, the ILS modulus of the same nano-laminates was increased by $87 \%$. Nevertheless, the results of nano-laminates tested by DNC [6] and SBS [8] methods in the same figure show significant improvements with 38\% and 27\%, respectively, even though the corresponding amounts of CNTs used are no more than $0.5 \mathrm{wt} \%$ and $0.25 \mathrm{wt} \%$. In particular, both nano-laminates are only $1 \mathrm{~mm}$ and $1.2 \mathrm{~mm}$ thick, respectively, so that the set-up and execution of individual tests could be very difficult with the much larger diameter 
loader in the case of SBS method. The ILS strength results of much thicker nano-laminates (around $6 \mathrm{~mm}$ thick) in Fig. 12 [12] that were tested by SBS method provide only very modest enhancement. In particular, they found that for the short CNT length of $1 \mu \mathrm{m}$ the presence of $1 \mathrm{wt} \%$ CNTs (the maximum amount reported) had almost no effect on ILS strength and the inclusion of dispersants with the same amount of CNTs increased ILS strength by around $12 \%$, which is modest. For the long CNT length of $10 \mu \mathrm{m}$, they found that the results of nano-laminates without dispersants are the same as those with the short CNT length. Once dispersants were added, the same degree of enhancement (13\%), similar to the case with the short CNT length, was obtained. This seems to suggest that a CNT length had little effect on ILS strength of nano-laminates, which is conter-intuitive. As the baseline ILS strength values of these carbon/epoxy host laminates are very low to begin with, these results seem to suggest that the quality of nano-laminates manufactured without consolidation pressure seems poor.

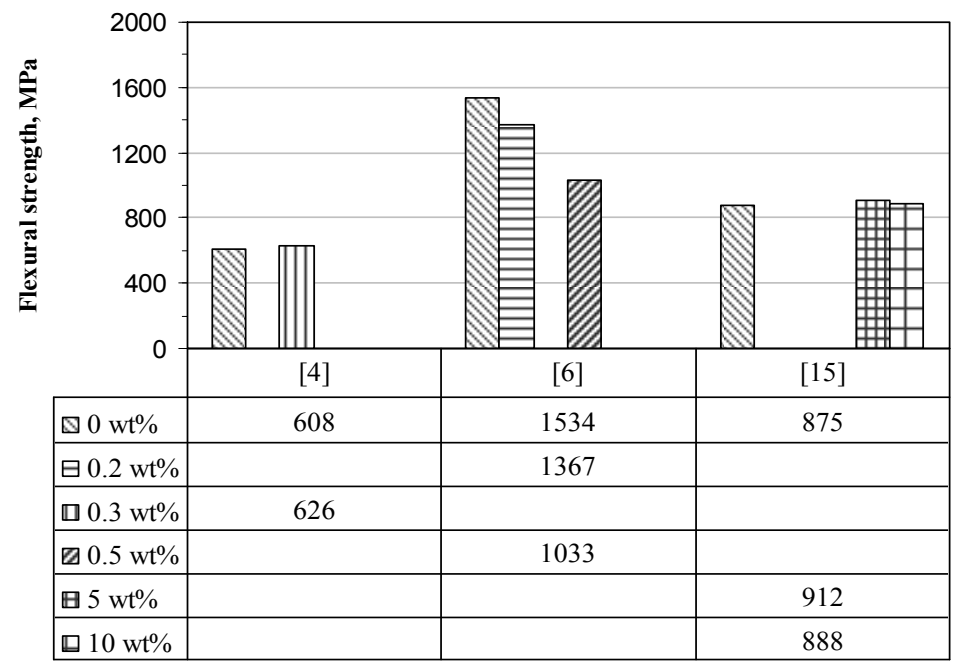

Fig. 10 Flexural strengths of nano-laminates with various carbon/epoxy laminate hosts from references $[4,6,15]$

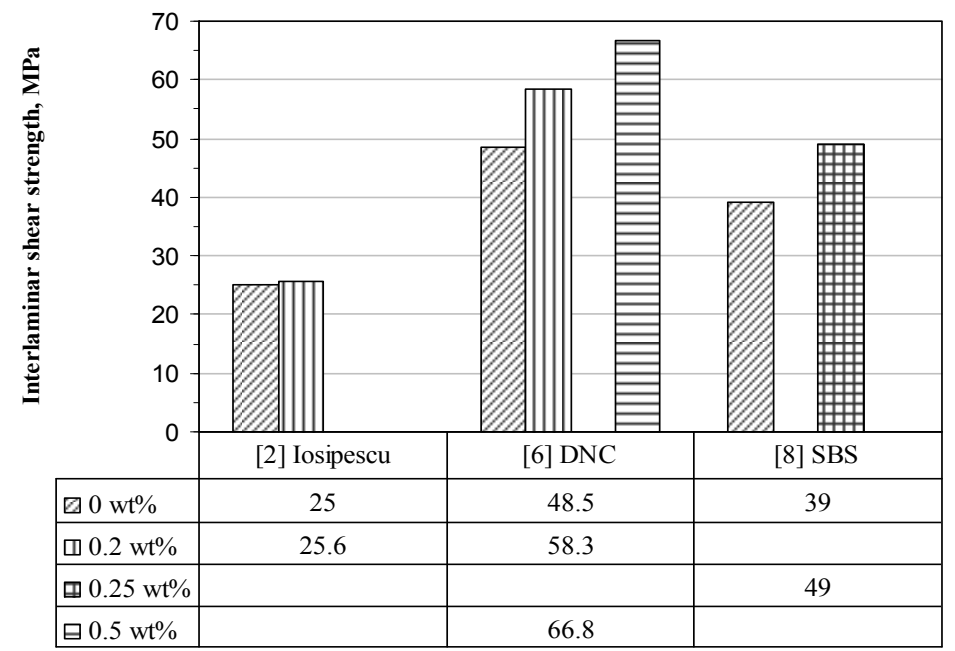

Fig. 11 ILSS of nano-laminates with carbon/epoxy hosts with various lay-ups by various test methods from references $[2,6,8]$

For GFRP host laminates $[3,9,13,14,16]$, the majority of nano-laminates (except for those in [3]) were tested using SBS method. The ILS strength results of thin nano-laminates (around $1 \mathrm{~mm}$ thick) exhibit from no effect [14] to modest effect of $11 \%$ [13] and 20\% [16], respectively, as shown in Figs 13 and 14, even though $12 \mathrm{wt} \%$ and $40 \mathrm{wt} \%$ CNTs were used in [14]. The authors in [14] also examined several CNT characteristics and effectiveness of CNT functionalisation. As shown in Fig. 13 and in Table 3, they found that ILS strengths of nano-laminates with 3wt $\%$ CNTs did not seem to be affected by either CNT configurations such as being long thin $(5-15 \mu \mathrm{m}$ in length and 10 - 
$30 \mathrm{~nm}$ in diameter) and short thick (1-2 $\mu \mathrm{m}$ in length and 40-60 $\mathrm{nm}$ in diameter) or surface treatment. The ILS strength results of thick nano-laminates (over $4 \mathrm{~mm}$ in [3] and around $5.8 \mathrm{~mm}$ thick in [9]) shown in Figs 15 and 16 show substantial enhancement. In [3], 18\% increase in ILS strength was obtained with $1 \mathrm{wt} \%$ CNTs using SBS method whereas $21 \%$ increase in ILS strength was obtained with the same amount of CNTs using CST method. The authors concluded that the CST method was more reliable than the SBS method due to more consistent failure modes observed in failed specimens. In addition, the effect of controlled orientation of CNTs on ILS strength was found to be small. In [9], the ILS strengths were found to be improved by $28 \%$ and $8 \%$ with very small amounts of CNTs at $0.1 \mathrm{wt} \%$ and $0.2 \mathrm{wt} \%$, respectively. The fact that doubling the amount of CNT led to a significantly lesser enhancement of ILS strength suggests that the degree of data unreliability is high. In addition, the authors found that coating CNTs with various functional groups enhanced ILS strengths of their respective nano-laminates only by modest amount (around 20\% in three out of four cases). Again, no microscopic corroborative evidence was given.

With alumina fibre satin weave fabric reinforced epoxy host [5], ILS strength of its nano-laminates with a thickness of around $2.1 \mathrm{~mm}$ was found, using SBS method, to be enhanced by $69 \%$ with $2 \mathrm{wt} \%$ CNTs. No microscopic corroborative evidence was given.

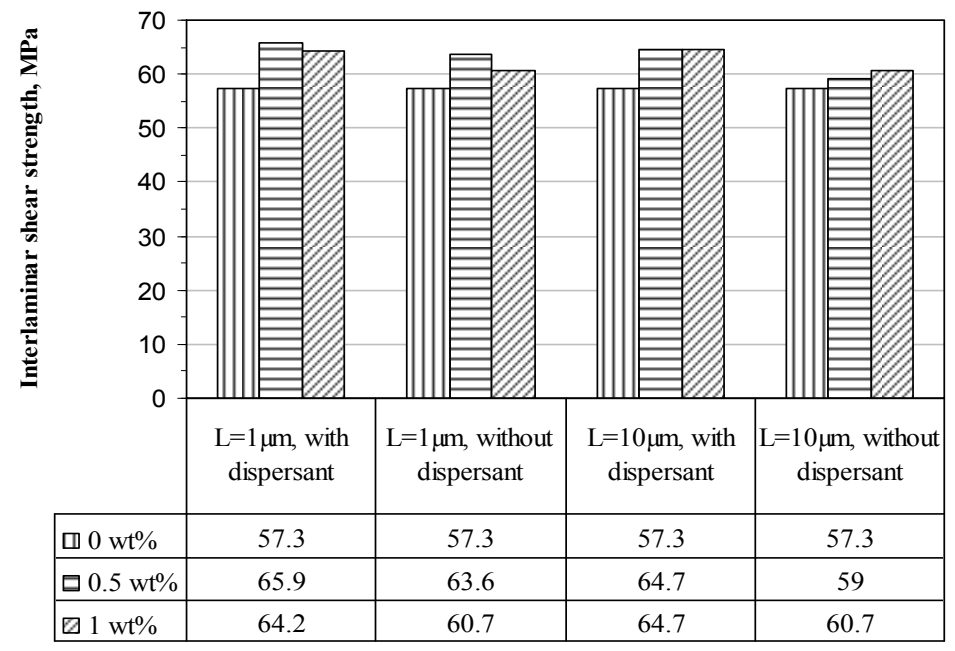

Fig. 12 ILSS of nano-laminates with carbon/epoxy host with various CNT and processing conditions from reference [12]

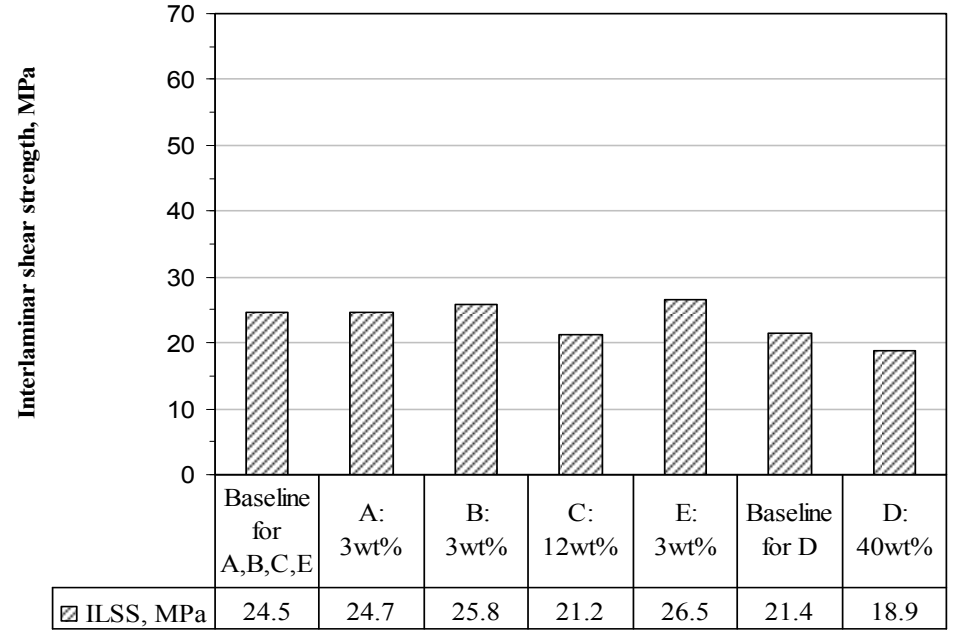

Fig. 13 ILSS of nano-laminates with E-glass/epoxy host with various CNT and processing conditions from reference [14] 


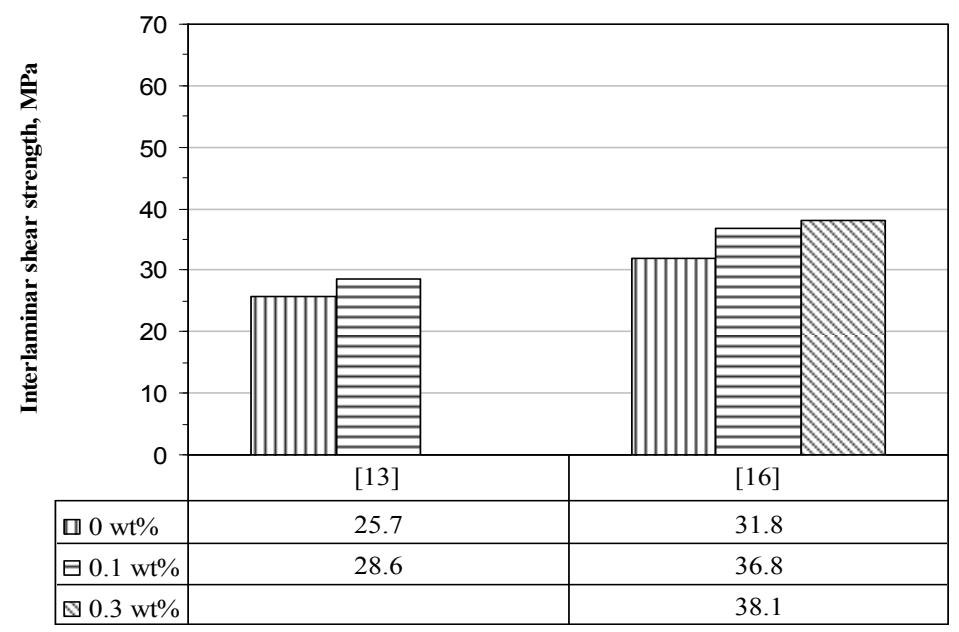

Fig. 14 ILSS of nano-laminates with quasi-isotropic E-glass/polyester [13] and E-glass/epoxy [16] laminate hosts

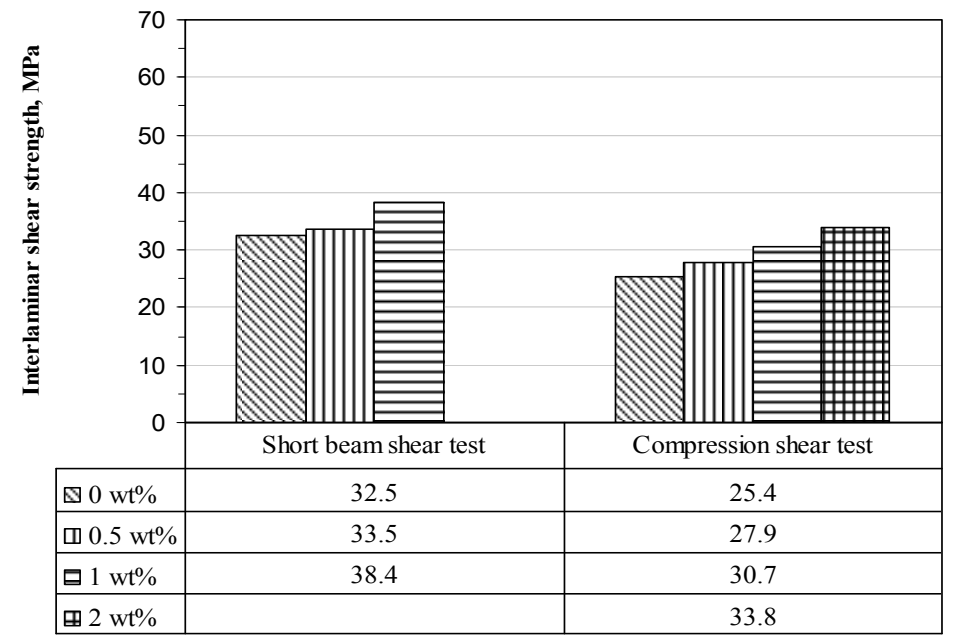

Fig. 15 ILSS of nano-laminates with E-glass/epoxy laminate host tested with two different methods from reference [3]

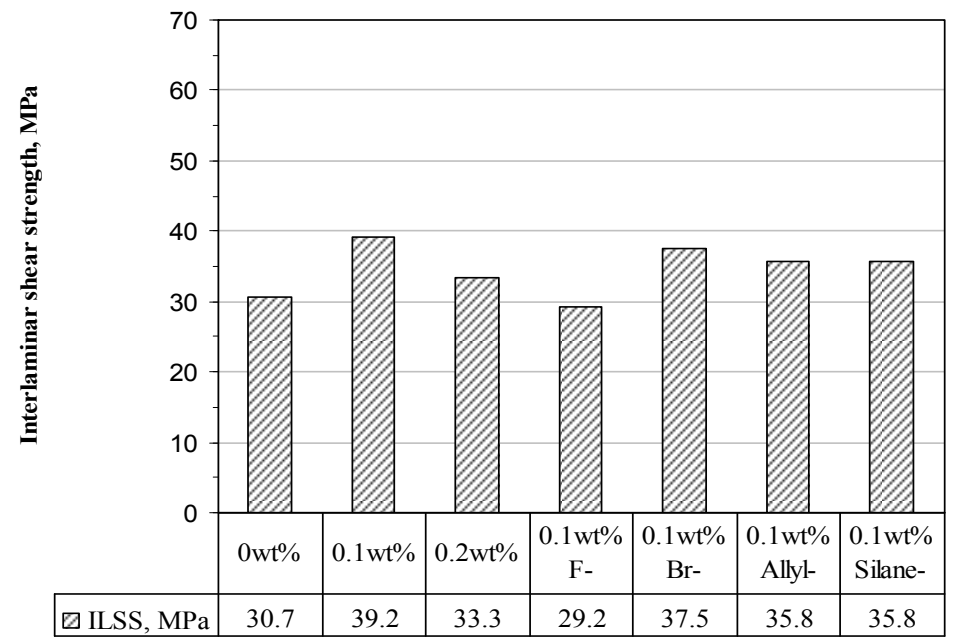

Fig. 16 ILSS of nano-laminates with E-glass/vinyl ester host with CNTs coated by various functional groups from reference [9] 


\subsection{Mode I fracture toughness}

The majority of nano-laminates $[1,11,13,15]$ tested for mode I fracture toughness used double cantilever beam (DCB) method following ASTM D5528 standard [31] while one [16] used compact tension (CT) method following ASTM D5045 standard [32]. Their critical strain energy release rates $\left(G_{\text {Ic }}\right)$ were taken as the measures of fracture toughness performance. All nano-laminates had some kind of epoxy matrix $[1,11,15,16]$ in the host laminates except for one which used polyester [13]. All numerical results of $G_{\text {Ic }}$ for nano-laminates are given in Table 3 and some of them are also presented graphically in Figs 17-19. The $G_{\text {Ic }}$ results of UD nano-laminates with two different lengths of CNTs from [1] exhibit very significant enhancement as shown in Fig. 17. For the CNT length of $60 \mu \mathrm{m}$, the average $G_{\text {Ic }}$ was increased by $152 \%$ for $0.4 \mathrm{wt} \%$ CNTs. Interestingly, a further increase of both CNT length up to 150 $\mu \mathrm{m}$ and amount of CNTs up to $1 \mathrm{wt} \%$ resulted in only $62 \%$ enhancement for average $G_{\mathrm{Ic}}$. Nevertheless, micrographs of fracture surfaces from failed specimens seem to show some CNT bridging that corroborated with the enhancement. In $[11,15], 98 \%$ enhancement of $G_{\text {Ic }}$ value from UD nano-laminates was reported with $5 \mathrm{wt} \% \mathrm{CNTs}$. In addition, the $G_{\text {Ic }}$ values were found to increase further in some cases when either additional CNT resin solution was sprinkled at the mid-plane ply interface during lay-up or additional resin film with $10 \mathrm{wt} \% \mathrm{CNT}$ was inserted at the mid-plane ply interface, as shown in Fig. 18. The authors reported that fracture surfaces of failed nano-laminate specimens were rougher than those of baseline laminates. Although the effect of CNT aspect ratio on $G_{\text {Ic }}$ was also investigated, there was no clear trend established to suggest that a larger aspect ratio provided greater enhancement. The $G_{\text {Ic }}$ results of QI nano-laminates show still significant but less enhancement. However, nano-laminates with polyester matrix [13] show no enhancement in $G_{\text {Ic }}$ with $0.1 \mathrm{wt} \%$ CNTs. The authors attributed this to the observation that the presence of CNTs limited the development of fibre bridging. Nevertheless, nano-laminates with epoxy matrix [16] in Fig. 19 show $42 \%$ enhancement of $G_{\text {Ic }}$ value with $0.3 \mathrm{wt} \%$ CNTs.

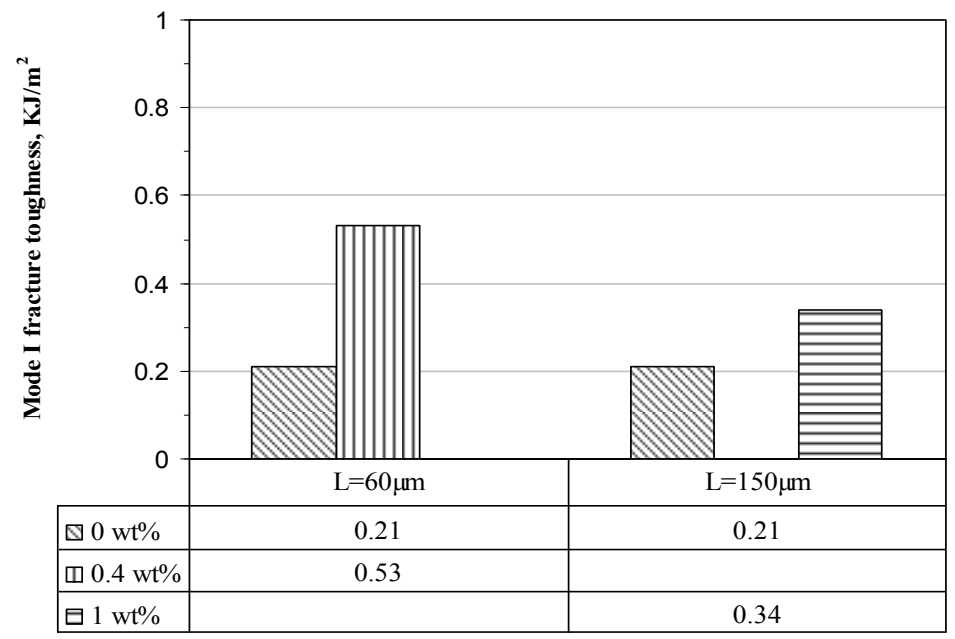

Fig. 17 Mode I fracture toughness $\left(G_{\mathrm{Ic}}\right)$ of nano-laminates with carbon/epoxy host with two CNT lengths from reference [1]

\subsection{Mode II fracture toughness}

Several mode II fracture toughness testing methods such as End Notch Flexure (ENF) [33] and 4-point End Notch Flexure (4ENF) [34] have been developed for composite laminates over the years. Although ENF method has been adopted in Europe and Japan as an official standard, it is yet to be adopted by ASTM in USA. In particular, 4ENF with stable crack propagation seems to be regarded as an improved method over ENF. Again, in both methods critical strain energy release rate $\left(G_{\text {IIc }}\right)$ is taken as the measure of fracture toughness performance. The majority $[1,11,15]$ of nano-laminates used some kind of epoxy matrix in their host laminates except for one [13] which used polyester. All numerical results of $G_{\text {IIc }}$ for nano-laminates are given in Table 3 and some of them are also presented graphically in Figs 20 and 21. Nano-laminates with UD carbon/epoxy hosts $[1,11,15]$ exhibit very significant enhancement in their $G_{\text {IIc }}$ as partially shown in Fig. 20 with $214 \%, 29 \%$ and $30 \%$ increase for $0.8 \mathrm{wt} \%$, 5wt $\%$ and $5 \mathrm{wt} \%$ CNTs, respectively. However, the $G_{\text {IIc }}$ results of both baseline laminates and nano-laminates in [1] were 
derived from the averages of two test data, respectively. In addition, the $G_{\text {IIc }}$ values in [11] were found to increase further when either additional CNT resin solution was sprinkled at the mid-plane ply interface during lay-up or additional resin film with $10 \mathrm{wt} \%$ CNT was inserted at the mid-plane ply interface, as shown in Fig. 21. The authors reported that fracture surfaces of failed nano-laminate specimens were rougher than those of baseline laminates. Although the effect of CNT aspect ratio on $G_{\text {IIc }}$ was also investigated, there was no clear trend established to suggest that the larger aspect ratio provided greater enhancement. On the contrary, nano-laminates with QI E-glass/polyester host [13] do not seem to show much enhancement $(8 \%)$ in their $G_{\text {IIc }}$ shown in the same figure for only $0.1 \mathrm{wt} \%$ CNTs. In addition to the fact that the amount of CNTs used in [13] was low, the thickness of the nano-laminates was also thin $(<2 \mathrm{~mm})$. These conditions did not form an ideal combination of set-up for testing $G_{\text {IIc }}$. Nevertheless, the authors attributed this to the presence of a large amount of 'hackles' on fracture surface rather than fibre bridging.

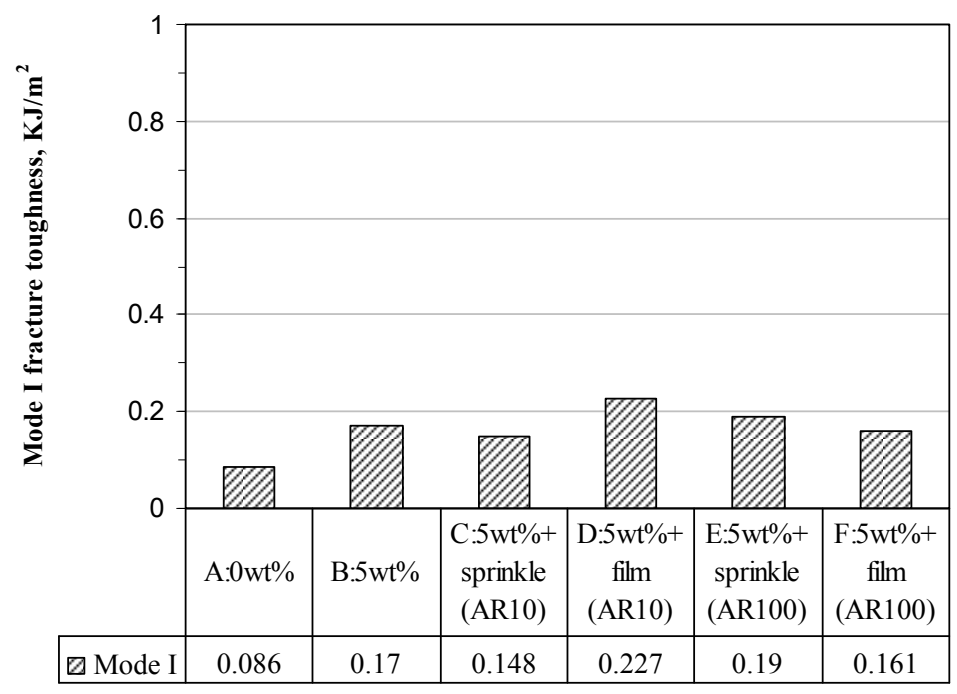

Fig. 18 Mode I fracture toughness $\left(G_{\text {Ic }}\right)$ of nano-laminates with carbon/epoxy laminate hosts with various processing conditions from references $[11,15]$

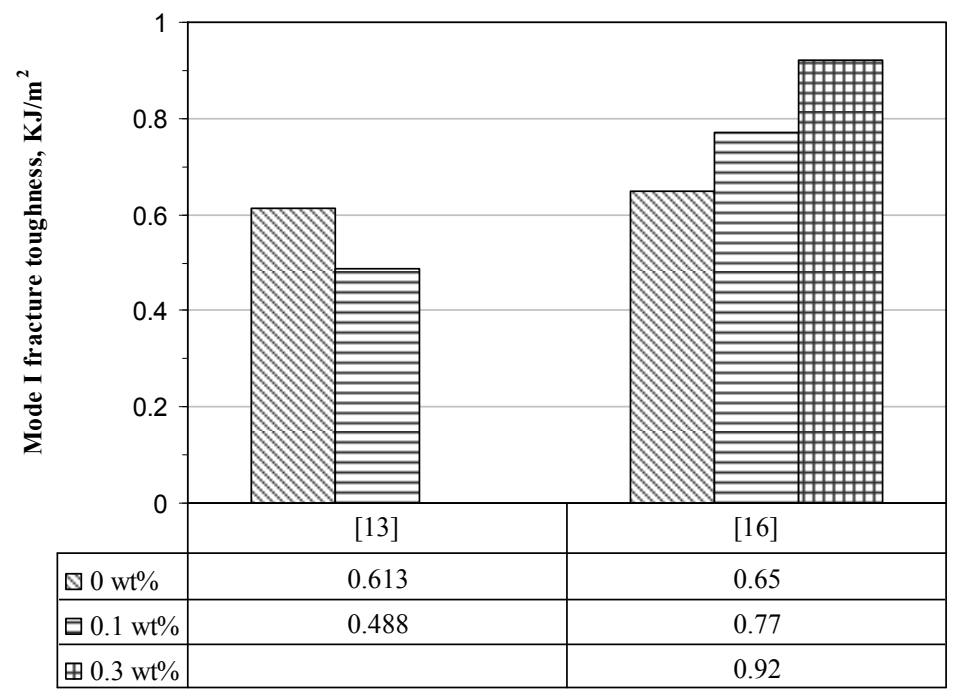

Fig. 19 Mode I fracture toughness $\left(G_{\mathrm{Ic}}\right)$ of nano-laminates with E-glass/polyester [13] and E-glass/epoxy [16] laminate hosts 


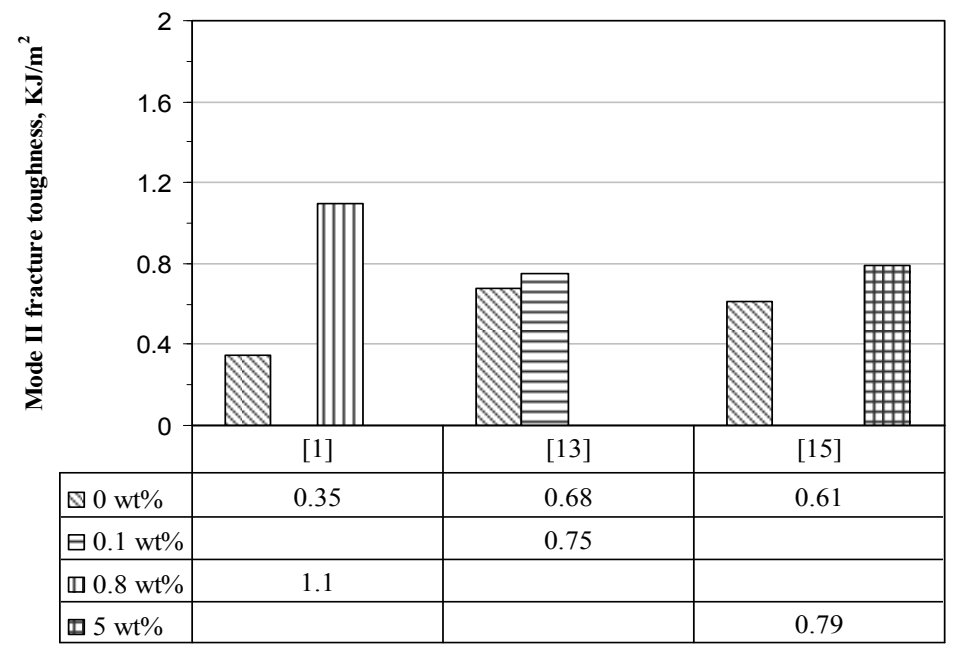

Fig. 20 Mode II fracture toughness $\left(G_{\text {IIc }}\right)$ of nano-laminates with carbon/epoxy [1], E-glass/polyester [13] and E-glass/epoxy [15] laminate hosts

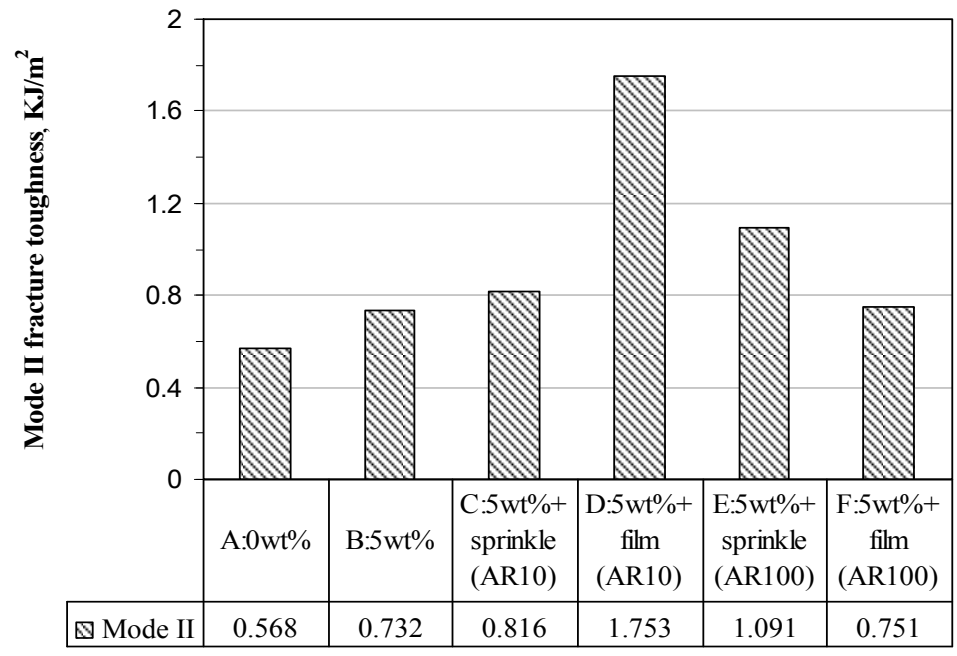

Fig. 21 Mode II fracture toughness $\left(G_{\text {IIc }}\right)$ of nano-laminates with UD carbon/epoxy laminate host with various CNT aspect ratios and processing conditions from reference [11]

\section{OTHER SIGNIFICANT MECHANICAL PERFORMANCE OF NANO-LAMINATES}

Impact damage resistance and damage tolerance are two important areas for advanced composite laminates. Although they are structural issues in general, these phenomena have been standardised over the years because of their significance in design and certification of composite aerospace structures. Impact damage resistance and damage tolerance are characterised respectively by relationships between impact energy and damage area and between CAI strength and either impact energy or damage area. Clearly, among all contributing factors, the size and through-the-thickness distribution of delaminations play a key role. The onset and propagation of delaminations are largely affected by ILS strength as well as fracture toughness values of the composite laminate.

These topics so far have received little attention. The only publication that investigated these phenomena of nanolaminates is from [15]. With up to $10 \mathrm{wt} \% \mathrm{CNTs}$, nano-laminates with 24 ply QI carbon/epoxy host were subjected to $20 \mathrm{~J}$ impact and did not show much difference to their baseline laminates in terms of impact damage area. As a result, their CAI strength was not improved. 


\section{CLOSING REMARKS}

Embedding CNTs in load-bearing composite laminates is an emerging field and has been proven to have tremendous potential in enhancing mechanical performance of composite laminates. A key driver in the development of nanolaminates at present has been the ability not only to control a uniform distribution and dispersion of CNTs and maintain their orientations within the laminate hosts but also to ensure that the CNTs are well bonded with the matrix of the laminate hosts. As our ability to control these processes and our understanding of enhancing mechanisms at the microscopic scale improve, there will be greater fulfilment to realise the potential of enhanced mechanical performance of nano-laminates.

As this state-of-the-art review indicates, the selective and uniform production of CNTs with specific dimensions and physical properties has yet to be achieved on a consistent basis. It is not yet completely clear what key parameters are in characterising mechanical performance of nano-laminates as a significant number of publications presented an incomplete description of essential information. Moreover, more research efforts seem to be focused on mechanical properties in tension, ILS and fracture toughness. While there are only two reports on in-plane compression, there is surprisingly none on in-plane shear, which is part of matrix-dominated mechanical behaviour. As expected, there is little enhancement found in reinforcement-dominated mechanical properties such as tension and flexure. Further investigations will be required for in-plane compression properties, though their primary deformation mechanisms are known to be shear-related. Significant enhancement, albeit with substantially varying degrees, has been reported for ILS strength and mode I and model-II fracture toughness. Equally, the lack of consistent characterisation in those properties is also visible. On some occasions, results are noticeably contradictory to one another.

Throughout the review, several key challenges have been identified and will be crucial to fulfil the potential of future nano-laminates. (1) A greater degree of orientation control for CNTs will be essential, as there is little control at present in the most fabrication processes of nano-laminates except for some cases associated with CVD. (2) A further scrutiny for suitability of mechanical testing methods/standards for some of mechanical properties such as ILS strength will be required. As a state of pure shear does not exist in gauge section of a beam specimen in the SBS method and thus ILS failure often occurs at one of the beam ends, it is the myth why such significant enhancement as reported in the most publications should occur. (3) A stronger emphasis must be put on post-mortem microscopic corroborative evidence as this is crucial for providing physical insight into the understanding of enhancing mechanisms in the mechanical performance of nano-laminates.

\section{REFERENCES}

[1] Garcia EJ, Wardle BL, Hart AJ. Joining prepreg composite interfaces with aligned carbon nanotubes. Composites: Part A 2008;39:1065-1070.

[2] Abot JL, Song Y, Schulz MJ, Shanov VN. Novel carbon nanotube array-reinforced laminated composite materials with higher interlaminar elastic properties. Composites Science and Technology 2008;68:2755-2760.

[3] Fan ZH, Santare MH, Advani SG. Interlaminar shear strength of glass fiber reinforced epoxy composites enhanced with multi-walled carbon nanotubes. Composites: Part A 2008;39:540-554.

[4] Zhou YX, Pervin F, Lewis L, Jeelani S. Fabrication and characterization of carbon/epoxy composites mixed with multi-walled carbon nanotubes. Materials Science and Engineering A 2008;475:157-165.

[5] Garcia EJ, Wardle BL, Hart AJ, Yamamoto N. Fabrication and multifunctional properties of a hybrid laminate with aligned carbon nanotubes grown in-situ. Composites Science and Technology 2008;68:2034-2041.

[6] Bekyarova E, Thostenson ET, Yu A, Itkis ME, Fakhrutdinov D, Chou TW, Haddon RC. Functionalized single-walled carbon nanotubes for carbon fiber-epoxy composites. J. Phys. Chem. C 2007;111:17865-17871.

[7] Kepple KL, Sanborn GP, Lacasse PA, Gruenberg KM, Ready WJ. Improved fracture toughness of carbon fiber composite functionalized with multi walled carbon nanotubes. Carbon 2008;46:2026-2033.

[8] Bekyarova E, Thostenson ET, Yu A, Kim H, Gao J, Tang J, Hahn HT, Chou TW, Itkis ME, Haddon RC. Multiscale carbon nanotube-carbon fiber reinforcement for advanced epoxy composites. Langmuir 2007;23:3970-3974.

[9] Zhu J, Imam A, Crane R, Lozao K, Khabashesku VN, Barrera EV. Processing a glass fiber reinforced vinyl ester composite with nanotube enhancement of interlaminar shear strength. Composites Science and 
Technology 2006;67:1509-1517.

[10] Yokozeki T, Iwahori Y, Ishiwata S. Matrix cracking behaviors in carbon fiber/epoxy laminates filled with cup-stacked carbon nanotubes (CSCNTs). Composites: Part A 2007;38:917-924.

[11] Yokozeki T, Iwahori Y, Ishibashi M, Yanagisawa T, Imai K, Arai M, Takahashi T, Enomoto K. Fracture toughness improvement of CFRP laminates by dispersion of cup-stacked carbon nanotubes. Composites Science and Technology 2008 in press.

[12] Cho J, Daniel IM, Dikin DA. Effects of block copolymer dispersant and nanotube length on reinforcement of carbon/epoxy composites. Composites: Part A 2008;39:1844-1850.

[13] Seyhan AT, Tanoglu M, Schulte K. Mode I and Mode II fracture toughness of E-glass non-crimp fabric/carbon nanotube (CNT) modified polymer based composites. Engineering Fracture Mechanics 2008;75:5151-5162.

[14] Sun LL, Zhao Y, Duan YX, Zhang ZG. Interlaminar shear property of modified glass fiber-reinforced polymer with different MWCNTs. Chineses J. of Aeronautics 2008;21:361-369.

[15] Yokozeki T, Iwahori Y, Ishiwata S, Eomoto K. Mechanical properties of CFRP laminates manufactured from unidirectional prepregs using CSCNT-dispersed epoxy. Composites: Part A 2007;38:2121-2130.

[16] Gojny FH, Malte HG, Wichmann MHG, Fiedler B, Bauhofer W, Schulte K. Influence of nano-modification on the mechanical and electrical properties of conventional fibre-reinforced composites. Composites: Part A 2005;36:1525-1535.

[17] Kim M, Park YB, Okoli OI, Zhang C. Processing, characterization, and modelling of carbon nanotubereinforced multiscale composites. Composites Science and Technology 2009; 69:335-342.

[18] Thostenson ET, Ren ZF, Chou TW. Advances in the science and technology of carbon nanotubes and their composites: a review. Composites Science and Technology 2001;61:1899-1912.

[19] Qian D, Wagner GJ, Liu WK. Mechanics of carbon nanotubes. Applied Mechanics Review 2002;55:495-531.

[20] Lau KT, Hui D. The revolutionary creation of new advanced materials-carbon nanotube composites. Composites: Part B 2002;33:263-271.

[21] Srivastava D, Wei CY. Nanomechanics of carbon nanotubes and composites. Applied Mechanics Review 2003;56:215-229.

[22] Eftekhari A, Jafarkhani P, Moztarzadeh F. High-yield synthesis of carbon nanotubes using a water-soluble catalyst support in catalytic chemical vapor deposition. Carbon 2006;44:1298-1352.

[23] Anon, Standard test method for tensile properties of polymer matrix composite materials, ASTM D3039, ASTM, 2008.

[24] Anon, Standard test method for compressive properties of polymer matrix composite materials with unsupported gage section by shear, ASTM D3410, ASTM, 2008.

[25] Anon, Standard test methods for flexural properties of unreinforced and reinforced plastics and electrical insulting materials, ASTM D790, ASTM, 2007.

[26] Anon, Standard test methods for in-plane shear response of polymer matrix composite materials by tensile test of a $\pm 45^{0}$ laminate, ASTM D3518, ASTM, 2007.

[27] Anon, Standard test methods for shear propertis of composite materials by the V-notched beam method, ASTM D5379, ASTM, 2005.

[28] Anon, Standard test method for short-beam strength of polymer matrix composite materials and their laminates, ASTM D2344, ASTM, 2006.

[29] Rosseli F, Santare MH. Comparison of the short beam shear (SBS) and interlaminar shear device (ISD) tests. Composites: Part A 1997;28:587-594.

[30] Anon, Standard test methods for in-plane shear strength of reinforced plastics, ASTM D3846, ASTM, 2008.

[31] Anon, Standard test methods for Mode I interlaminar fracture toughness of unidirectional fibre-reinforced polymer matrix composites, ASTM D5528, ASTM, 2007.

[32] Anon, Standard test methods for plane-strain fracture toughness and strain energy release rate of plastic materials, ASTM D5045 ASTM, 1999.

[33] Russell AJ, Street KN. Factors affecting the interlaminar fracture energy of graphite/epoxy laminates. Proc. of ICCM4, pp279-286, Tokyo, ASM International, 1982.

[34] Adams DF, Carlsson LA, Pipes RB. Experimental characterization of advanced composite materials, CRC Press, Boca Raton, 2003. 
Table 1 Physical characteristics of laminate hosts and carbon nanotubes (CNTs) in nano-laminates

\begin{tabular}{|c|c|c|c|c|c|c|c|}
\hline \multirow[t]{3}{*}{ Ref. } & \multirow{3}{*}{$\begin{array}{c}\text { Manufacture } \\
\text { techniques }\end{array}$} & \multicolumn{2}{|c|}{ Host composite materials } & \multicolumn{4}{|c|}{ CNT } \\
\hline & & $\begin{array}{l}\text { Host laminate } \\
\text { and lay-up }\end{array}$ & $\begin{array}{c}\text { No of } \\
\text { plies/thickness } \\
(t \text { ply thickness in } \\
\text { mm })\end{array}$ & $\begin{array}{c}\text { CNT type with } \\
- \\
\text { functional } \\
\text { group }\end{array}$ & $\begin{array}{l}\text { Produc. } \\
\text { method }\end{array}$ & $\begin{array}{c}\text { Length }(l) \\
\text { and/or diameter } \\
(d)\end{array}$ & Location \\
\hline & & - & $-/ \mathrm{mm}$ & - & - & $\mu \mathrm{m} / \mathrm{nm}$ & - \\
\hline$[1]$ & Autoclave & $\begin{array}{l}\text { A: IM7/Ep UD } \\
\text { B: AS4/Ep UD }\end{array}$ & $24 / 3 \mathrm{~mm}$ & CNT forest & CVD & $l=60,120,150$ & $\begin{array}{l}\text { CNTs in resin of } 12^{\text {th }} \text { and } 13^{\text {th }} \\
\text { plies }\end{array}$ \\
\hline [2] & $\begin{array}{c}\text { Compression } \\
\text { moulding }\end{array}$ & PW T300/Ep & $8 / 3.5 \mathrm{~mm}$ & MWNT & CVD & $l=50$ & CNTs in $4^{\text {th }}$ or $5^{\text {th }}$ ply \\
\hline [3] & \begin{tabular}{|l|} 
A:VARTM \\
B: IDVART
\end{tabular} & PW E-glass/Ep & $\begin{array}{c}8 / 4.4(\mathrm{~B}) \& 6.8 \\
\mathrm{~mm}(\mathrm{~A})\end{array}$ & MWNT & CVD & $l=15$ & CNTs in resin \\
\hline [4] & VARTM & SW Carbon/Ep & $4 / 2 \mathrm{~mm}(t=0.23)$ & MWNT & - & $l=3-10$ & CNTs in resin \\
\hline [5] & Hand lay-up & SW Al./Ep AP & $4 / 2.1 \mathrm{~mm}$ & CNT & CVD & $l=30$ & CNTs in resin \\
\hline [6] & VARTM & IM7/Ep UD & $8 / 1 \mathrm{~mm}$ & SWNT-COOH & EAD & $l=0.75$ & CNTs in resin \\
\hline [7] & Hand lay-up & PW T300/Ep & $4 / 2 \mathrm{~mm}$ & MWNT & CVD & - & CNTs on both sides of each ply \\
\hline [8] & VARTM & PW IM7/Ep & $4 / 1.2 \mathrm{~mm}$ & MWNT & CVD & $l=2 \sim 6$ & CNTs on both sides of each ply \\
\hline [9] & VARTM & PW E-glass/VE & $10 / 5.7-6.0 \mathrm{~mm}$ & SWNT & CVD & $d=1.1$ & CNTs onto 2 plies at mid-plane \\
\hline [10] & Autoclave & T700/Ep CP & $\begin{array}{c}8 / 2 \mathrm{~mm} \\
\text { A: }\left[0_{2} / 90_{2}\right]_{\mathrm{s}} \\
\text { B: }\left[90_{2} / 0_{2}\right]_{\mathrm{s}} \\
\end{array}$ & CSCNT & CVD & $d=70-80$ & CNTs in resin \\
\hline [11] & Autoclave & T700/Ep UD & $36 / 4(t=0.12)$ & CSCNT & CVD & $d=70-80$ & $\begin{array}{l}\text { CNTs in resin \& at } 18^{\text {th }}-19^{\text {th }} \\
\text { ply interface }\end{array}$ \\
\hline [12] & Autoclave & 5HS AS4/Ep & $48 /-$ & MWNT & CVD & A: $l=1 \mathrm{~B}: l=10$ & CNTs in resin \\
\hline [13] & VARTM & E-glass/Po QI & $8 /-$ & MWNT-NH 2 & - & - & CNTs in resin \\
\hline$[14]$ & $\begin{array}{c}\text { Compression } \\
\text { moulding }\end{array}$ & PW E-glass/Ep & $\begin{array}{c}\mathrm{A}, \mathrm{B}, \mathrm{C} \text { and E: } 6 \\
\text { plies, } \\
\text { D: } 5 \text { plies, } \\
(t=0.16)\end{array}$ & MWNT & - & $\begin{array}{l}\mathrm{A}, \mathrm{D} \text { and } \mathrm{E}: \\
d=10-30, l=5-15 \\
\mathrm{~B} \text { and } \mathrm{C}: \\
d=40-60, l=1-2\end{array}$ & $\begin{array}{l}\text { A, B C and E: CNTs in resin } \\
\text { C: additional oriented CNTs } \\
\text { at mid-plane } \\
\text { D: one CNT composite film } \\
\text { at } 4 \text { ply interfaces }\end{array}$ \\
\hline$[15]$ & Autoclave & $\begin{array}{l}\text { T700/Ep UD } \\
\text { QI }\end{array}$ & $\begin{array}{c}16 / 2 \mathrm{~mm} \text { and } \\
36 / 4 \mathrm{~mm} \\
24 / 3 \mathrm{~mm}\end{array}$ & CSCNT & CVD & $d=70-80$ & CNTs in resin \\
\hline [16] & RTM & E-glass/Ep QI & $4 /-$ & DWNT-NH & - & $d=2.8$ & CNTs in resin \\
\hline [17] & VARTM & SW IM7/Ep & $4 / 1 \mathrm{~mm}$ & CNT & - & - & CNTs in resin \\
\hline
\end{tabular}

UD, CP, AP and QI denote unidirectional, crossply, angleply and quasi-isotropic lay-up, respectively.

PW, SW and 5HS denote plain weave, satin weave and 5 harness satin, respectively.

Al. denotes alumina fibres. Ep, Po and VE denote epoxy, polyester and vinyl ester, respectively.

SWNT, DWNT, MWNT and CSCNT denote single-walled, double-walled, multi-walled and cup-stacked carbon nanotubes, respectively.

CVD and EAD denote chemical vapor deposition and electric arch discharge, respectively. 
Table 2 Mechanical properties in tension, in-plane compression and flexure of nano-laminates

\begin{tabular}{|c|c|c|c|c|c|c|c|}
\hline \multirow[b]{2}{*}{ Ref. } & \multicolumn{2}{|c|}{ Tension } & \multicolumn{2}{|r|}{ Compression } & \multicolumn{2}{|c|}{ Flexure } & \multirow[b]{2}{*}{ Test method ${ }^{*}$} \\
\hline & $\begin{array}{c}\text { Tensile modulus } \\
\text { GPa }\end{array}$ & $\begin{array}{c}\text { Tensile strength } \\
\mathrm{MPa}\end{array}$ & $\begin{array}{l}\text { Comp. } \\
\text { modulus } \\
\text { GPa }\end{array}$ & $\begin{array}{l}\text { Compressive strength } \\
\mathrm{MPa}\end{array}$ & $\begin{array}{l}\text { Flexure } \\
\text { modulus } \\
\text { GPa }\end{array}$ & $\begin{array}{l}\text { Flexure } \\
\text { strength } \\
\mathrm{MPa}\end{array}$ & \\
\hline [4] & - & - & - & - & $\begin{array}{l}\text { BS 63.0, } \\
\text { NL 66.1 } \\
(0.3 \mathrm{wt} \%)\end{array}$ & $\begin{array}{l}\text { BS 608, } \\
\text { NL } 626 \\
(0.3 w t \%)\end{array}$ & $\begin{array}{c}\text { ASTM D790 } \\
L / t=16\end{array}$ \\
\hline [6] & - & - & - & - & $\begin{array}{c}\text { BS 106, } \\
\text { NL } 106 \\
(0.2 \mathrm{wt} \%), \\
\text { NL } 109 \\
(0.5 \mathrm{wt} \%)\end{array}$ & $\begin{array}{l}\text { BS } 1534, \\
\text { NL } 1367 \\
(0.2 \mathrm{wt} \%), \\
\text { NL } 1033 \\
(0.5 \mathrm{wt} \%)\end{array}$ & $\begin{array}{c}\text { Flexure } \\
\text { ASTM D790 } \\
L / t=32\end{array}$ \\
\hline [8] & $\begin{array}{l}\text { BS } 67.5, \text { NL } 70 \\
\quad(0.25 \mathrm{wt} \%)\end{array}$ & $\begin{array}{l}\text { BS } 600, \text { NL } 580 \\
\quad(0.25 \mathrm{wt} \%)\end{array}$ & - & - & - & - & $\begin{array}{l}\text { Tension } \\
\text { ASTM } \\
\text { D3039 }\end{array}$ \\
\hline [10] ] & $\begin{array}{c}\text { A: BS 131, } \\
\text { NL } 129(5 \mathrm{wt} \%), \\
\text { NL } 131(12 \mathrm{wt} \%) \\
\text { B: BS 8.61, } \\
\text { NL } 9.11(5 \mathrm{wt} \%), \\
\text { NL } 9.08(12 \mathrm{wt} \%)\end{array}$ & $\begin{array}{c}\text { B: BS 51.2, } \\
\text { NL57.9 (5 } \mathrm{wt} \%) \\
\text { NL 55.1 (12 } 12 \mathrm{t} \%)\end{array}$ & - & - & - & - & - \\
\hline [12] ] & - & - & . & 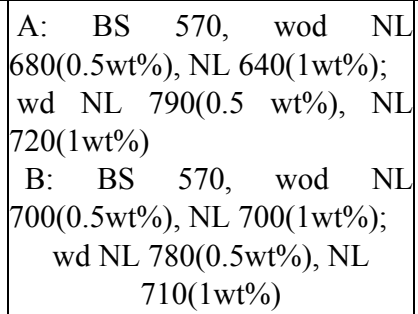 & - & - & $\begin{array}{l}\text { Compression } \\
\text { NU fixture }\end{array}$ \\
\hline$[15]$ & \begin{tabular}{|c|}
$0^{0}:$ BS $131, \mathrm{NL} 129$ \\
$(5 \mathrm{wt} \%)$ \\
$90^{0}:$ BS $8.6, \mathrm{NL} 9.1$ \\
$(5 \mathrm{wt} \%)$ \\
QI: BS 46.5, NL \\
$47.9(5 \mathrm{wt} \%), \mathrm{NL}$ \\
$48.3(10 \mathrm{wt} \%)$
\end{tabular} & \begin{tabular}{|c|}
$90^{\circ}:$ BS $51.2, \quad \mathrm{NL}$ \\
$57.9(5 \mathrm{wt} \%)$ \\
QI: BS 848, \\
NL $844(5 \mathrm{wt} \%)$, \\
NL $850(10 \mathrm{wt} \%)$
\end{tabular} & \begin{tabular}{|c|} 
QI: BS \\
42.9, \\
NL 43.2 \\
$(5 \mathrm{wt} \%), \mathrm{NL}$ \\
45.1 \\
$(10 \mathrm{wt} \%)$
\end{tabular} & $\begin{array}{c}\text { QI: BS 488, NL } 501(5 \mathrm{wt} \%) \\
\text { NL } 539(10 \mathrm{wt} \%)\end{array}$ & \begin{tabular}{|l} 
QI: BS 53.0, \\
NL 55.1 \\
$(5 \mathrm{wt} \%)$, \\
NL 55.8 \\
$(10 \mathrm{wt} \%)$
\end{tabular} & $\begin{array}{l}\text { QI: BS 875, } \\
\text { NL } 912 \\
(5 \mathrm{wt} \%,)^{2} \\
\text { NL } 888 \\
(10 \mathrm{wt} \%)\end{array}$ & $\begin{array}{c}\text { Tension } \\
\text { ASTM } \\
\text { D3039, } \\
\text { Compression } \\
\text { NAL, } \\
\text { Flexure JIS } \\
L / t=27\end{array}$ \\
\hline$[16]$ & $\begin{array}{c}0^{0}: \mathrm{BS} 25.5, \mathrm{NL} \\
26.4(0.1 \mathrm{wt} \%) \\
90^{\circ}: \mathrm{BS} 12.3, \mathrm{NL} \\
13.2(0.1 \mathrm{wt} \%)\end{array}$ & \begin{tabular}{|c|}
$0^{0}:$ BS 573, NL 536 \\
$(0.1 \mathrm{wt} \%)$ \\
$90^{0}: \mathrm{BS} 170, \mathrm{NL} 170$ \\
$(0.1 \mathrm{wt} \%)$
\end{tabular} & - & - & - & - & $\begin{array}{l}\text { Tension DIN } \\
\text { EN 527.1/2 }\end{array}$ \\
\hline [17] & $\begin{array}{c}\text { BS 60.2, } \\
\text { NL 59.4 (P2) } \\
(0.3 \mathrm{wt} \%) \\
\text { NL 59.9 (P3) }(0.3 \\
\text { wt } \%)\end{array}$ & $\begin{array}{c}\text { BS 574.1, } \\
\text { NL 532.1 (P2) } \\
(0.3 \mathrm{wt} \%), \\
\text { NL 562.7 (P3) } \\
(0.3 \mathrm{wt} \%)\end{array}$ & - & - & \begin{tabular}{|c|} 
BS 39.5 \\
NL 44.1(P2), \\
NL 42.8 (P3)
\end{tabular} & $\begin{array}{l}\text { BS 627 } \\
\text { NL 741 } \\
\text { (P2), } \\
\text { NL 682 } \\
\text { (P3) }\end{array}$ & $\begin{array}{c}\text { Tension } \\
\text { ASTM } \\
\text { D3039, } \\
\text { Flexure } \\
\text { ASTM D790 } \\
L / t=25\end{array}$ \\
\hline
\end{tabular}

BS and NL denote baseline and nano-laminates, respectively. wd and wod denote with and without dispersant, respectively. P2 and P3 denote panel 2 and panel 3 in [17], respectively. ${ }^{*} \mathrm{NU}$ and NAL denote Northwestern University and National Aerospace Laboratory in Japan, respectively. 
Table 3 Mechanical properties in ILS, mode-I and mode-II fracture toughness of nano-laminates

\begin{tabular}{|c|c|c|c|c|c|}
\hline \multirow[b]{2}{*}{ Ref } & \multicolumn{2}{|c|}{ ILS modulus (ILSM) and strength (ILSS) } & \multicolumn{2}{|c|}{ Fracture toughness } & \multirow[b]{2}{*}{ Test method $^{*}$} \\
\hline & ILSM, GPa & ILSS, MPa & Mode-I $G_{\mathrm{Ic}}, \mathrm{kJ} / \mathrm{m}^{2}$ & Mode-II $G_{\text {IIc }}, \mathrm{kJ} / \mathrm{m}^{2}$ & \\
\hline [1] & - & - & $\begin{array}{c}\text { C }(60 \mu \mathrm{m}): \mathrm{BS} 0.21, \mathrm{NL} \\
0.53(0.4 \mathrm{wt} \%) \\
\mathrm{E}(150 \mu \mathrm{m}): \mathrm{BS} 0.21, \mathrm{NL} \\
0.34(1 \mathrm{wt} \%)\end{array}$ & $\begin{array}{c}\mathrm{D}(120 \mu \mathrm{m}): \mathrm{BS} \\
0.35 \\
\mathrm{NL} 1.1(0.8 \mathrm{wt} \%)\end{array}$ & $\begin{array}{l}\text { DCB ASTM } \\
\text { D5528, } \\
\text { 4ENF }\end{array}$ \\
\hline [2] & $\begin{array}{c}\text { BS } 4.5, \mathrm{NL} \\
8.4 \\
(0.2 \mathrm{wt} \%) \\
\end{array}$ & BS 25.0, NL $25.6(0.2 \mathrm{wt} \%)$ & - & - & $\begin{array}{l}\text { Iosipescu ASTM } \\
\text { D5379 }\end{array}$ \\
\hline [3] & - & $\begin{array}{c}\text { A-SBS: BS 32.5, NL } 33.5(0.5 \mathrm{wt} \%), \\
\text { NL 38.4 (1wt } \%) \\
\text { B-CST: BS 25.4, NL 27.9 (0.5wt\%), } \\
\text { NL 30.7 (1wt\%), NL } 33.8(2 \mathrm{wt} \%) \\
\end{array}$ & - & - & $\begin{array}{c}\text { SBS ASTM D2344 } \\
L / t=4, \\
\text { CST }\end{array}$ \\
\hline [5] & - & BS 20.1, NL $33.8(2 \mathrm{wt} \%)$ & - & - & $\begin{array}{c}\text { SBS ASTM D2344 } \\
L / t=4\end{array}$ \\
\hline [6] & - & $\begin{array}{c}\text { BS 48.5, NL } 58.3(0.2 \mathrm{wt} \%), \text { NL } 66.8 \\
(0.5 \mathrm{wt} \%)\end{array}$ & - & - & \begin{tabular}{|c|} 
DNC ASTM \\
D3846 \\
\end{tabular} \\
\hline [7] & - & - & $\begin{array}{c}\text { Warp: BS } 0.443, \mathrm{NL} \\
0.645 \\
\end{array}$ & - & DCB ASTM D5528 \\
\hline [8] & - & BS 39, NL $49(0.25 \mathrm{wt} \%)$ & - & - & $\begin{array}{c}\text { SBS ASTM D2344 } \\
L / t=4 \\
\end{array}$ \\
\hline [9] & - & $\begin{aligned} \text { SWNT: BS } 30.7 \text { NL } 39.2(0.1 \mathrm{wt} \%), \\
33.3(0.2 \mathrm{wt} \%), \\
\text { F-SWNT: } 29.2(0.1 \mathrm{wt} \%), \text { Br-SWNT: } \\
37.5(0.1 \mathrm{wt} \%), \\
\text { All-SWNT: } 35.8(0.1 \mathrm{wt} \%), \text { Sil-SWNT: } \\
35.8(0.1 \mathrm{wt} \%) \\
\end{aligned}$ & - & - & $\begin{array}{c}\text { SBS ASTM D2344 } \\
L / t=5\end{array}$ \\
\hline [11] & - & - & \begin{tabular}{|c|} 
A: BS 0.086 B: 0.17 \\
$(5 \mathrm{wt} \%)$ \\
C: $0.148(5 \mathrm{wt} \%)$ D: 0.227 \\
$(5 \mathrm{wt} \%)$ \\
E: $0.19(5 \mathrm{wt} \%)$ F: 0.161 \\
$(5 \mathrm{wt} \%)$ \\
\end{tabular} & \begin{tabular}{|c|} 
A: BS 0.568 B: \\
$0.732(5 \mathrm{wt} \%) \mathrm{C}:$ \\
$0.816(5 \mathrm{wt} \%)$ \\
D: $1.753(5 \mathrm{wt} \%) \mathrm{E}:$ \\
$1.091(5 \mathrm{wt} \%) \mathrm{F}:$ \\
$0.751(5 \mathrm{wt} \%)$ \\
\end{tabular} & $\begin{array}{l}\text { DCB ASTM } \\
\text { D5528, } \\
\text { ENF }\end{array}$ \\
\hline [12] & - & \begin{tabular}{|c|} 
A: BS 57.3, wod NL 63.6 $(0.5 \mathrm{wt} \%)$ \\
NL $60.7(1 \mathrm{wt} \%)$ \\
wd NL 65.9 $(0.5 \mathrm{wt} \%) ;$ NL $64.2(1 \mathrm{wt} \%)$ \\
B: BS 57.3, wod NL 59.0 $(0.5 \mathrm{wt} \%) ;$ \\
NL 60.7 (1wt\%), NL 64.7 (0.5wt\%); \\
NL 64.7 (1wt\%) \\
\end{tabular} & \begin{tabular}{|l|}
- \\
\end{tabular} & - & $\begin{array}{c}\text { SBS ASTM D2344 } \\
L / t=4\end{array}$ \\
\hline [13] & - & BS 25.7, NL $28.6(0.1 \mathrm{wt} \%)$ & $\begin{array}{c}\text { BS } 0.613, \text { NL } 0.488 \\
(0.1 \mathrm{wt} \%)\end{array}$ & $\begin{array}{l}\text { BS } 0.68, \text { NL } 0.75 \\
\quad(0.1 \mathrm{wt} \%)\end{array}$ & $\begin{array}{c}\text { SBS ASTM D2344 } \\
L / t=5 \\
\text { DCB ASTM } \\
\text { D5288, ENF } \\
\end{array}$ \\
\hline [14] & - & $\begin{array}{c}\text { (1) BS 24.5, A NL 24.7 (3wt\%), B NL } \\
25.8(3 \mathrm{wt} \%), \\
\text { E NL 26.5 (3wt\%), C NL } 21.2 \\
(12 \mathrm{wt} \%) ; \\
\text { (2) BS 21.4, D NL } 18.9(40 \mathrm{wt} \%) \\
\end{array}$ & - & - & $\begin{array}{c}\text { SBS ASTM D } 2344 \\
L / t=5\end{array}$ \\
\hline [15] & - & - & $\begin{array}{c}\text { UD: BS } 0.09, \text { NL } 0.17 \\
(5 \mathrm{wt} \%)\end{array}$ & $\begin{array}{l}\text { UD BS } 0.61, \mathrm{NL} \\
0.79(5 \mathrm{wt} \%)\end{array}$ & $\begin{array}{l}\text { DCB ASTM } \\
\text { D5528, ENF }\end{array}$ \\
\hline [16] & - & $\begin{array}{c}\mathrm{BS} 31.8, \mathrm{NL} 36.8(0.1 \mathrm{wt} \%), \text { NL } 38.1 \\
(0.3 \mathrm{wt} \%)\end{array}$ & $\begin{array}{c}\text { BS } 0.65, \text { NL } 0.77 \\
(0.1 \mathrm{wt} \%) \\
\text { NL } 0.92(0.3 \mathrm{wt} \%)\end{array}$ & - & $\begin{array}{c}\text { SBS ASTM D } 2344 \\
L / t=5, \text { CT ASTM } \\
\text { D5045 }\end{array}$ \\
\hline
\end{tabular}

